\title{
Article \\ Influence of Wind Barriers with Different Curvatures on Crosswind Aerodynamic Characteristics of a Train-Bridge System
}

\author{
Ping Lou ${ }^{1,2, *(1)}$, Wei Tao ${ }^{1}$, Chenzhi Cai ${ }^{1,3}$, Xuhui He ${ }^{1,3} \mathbb{C}$, Yunfeng Zou ${ }^{1,3}$ and Yuyan $\mathrm{Ai}^{1}$ \\ 1 School of Civil Engineering, Central South University, Changsha 410075, China; 154801059@csu.edu.cn (W.T.); \\ chenzhi.cai@csu.edu.cn (C.C.); xuhuihe@csu.edu.cn (X.H.); yunfengzou@csu.edu.cn (Y.Z.); \\ 214812261@csu.edu.cn (Y.A.) \\ 2 Key Laboratory of Heavy Railway Engineering Structure of Education Ministry, Central South University, \\ Changsha 410075, China \\ 3 Hunan Provincial Key Laboratory for Disaster Prevention and Mitigation of Rail Transit Engineering Structure, \\ Central South University, Changsha 410075, China \\ * Correspondence: pinglou@mail.csu.edu.cn
}

check for updates

Citation: Lou, P.; Tao, W.; Cai, C.; He, X.; Zou, Y.; Ai, Y. Influence of Wind Barriers with Different Curvatures on Crosswind Aerodynamic Characteristics of a Train-Bridge System. Appl. Sci. 2022, 12, 1747. https://doi.org/10.3390/ app12031747

Academic Editors: Felix Nieto, John Owen and Ole Andre Øiseth

Received: 28 December 2021

Accepted: 5 February 2022

Published: 8 February 2022

Publisher's Note: MDPI stays neutral with regard to jurisdictional claims in published maps and institutional affiliations.

Copyright: (C) 2022 by the authors. Licensee MDPI, Basel, Switzerland. This article is an open access article distributed under the terms and conditions of the Creative Commons Attribution (CC BY) license (https:// creativecommons.org/licenses/by/ $4.0 /)$.

\begin{abstract}
Wind barriers can effectively reduce the risk of overturning and derailment of high-speed trains running on a bridge under crosswind. However, it can adversely affect the wind resistance of the bridge. There are few studies on the aerodynamic performance of curved wind barriers. In this paper, the effects of curved wind barriers with four curvatures $(0,0.2,0.35$, and 0.50$)$ and different train-bridge combinations on the crosswind aerodynamic characteristics of a train-bridge system are investigated. The results show that the curved wind barrier can significantly reduce the wind speed below a certain height on the bridge deck. The curved wind barrier with small curvature can better reduce the aerodynamic force of the train; however, it greatly increases the aerodynamic force of the bridge. A wind barrier with a curvature of 0.35 is recommended because it takes into account the aerodynamic characteristics of the train and bridge at the same time. The porosity of a wind barrier greatly influences the aerodynamic performance of the train on the track of the windward side of the bridge, while the wind barrier has little effects on the train on the track of the leeward side of the bridge. The aerodynamic performance of the train on the track of the windward side of the bridge is less affected by whether or not a train on the track of the leeward side of the bridge is present.
\end{abstract}

Keywords: curved wind barrier; curvature; numerical simulation; train-bridge system; aerodynamic characteristics

\section{Introduction}

As there has been a rapid development in high-speed railway systems in recent decades, the crosswind stability of trains has become a main concern [1-4]. In order to ensure a high-speed railway track's smoothness, the bridge mileage accounts for a large proportion.. However, the trains run on bridges that are far above the ground, which brings about a more complex wind environment and they are more affected by crosswind. High-speed trains running in a strong crosswind environment are prone to accidents, such as overturning and derailment, which cause heavy economic losses and casualties. The wind barrier can significantly reduce the wind speed in the train running area and ensure the running safety of the train, which is an economical and efficient wind protection measure [5-9].

Numerical simulation and wind tunnel tests are usually used to study the aerodynamic performance of the wind barrier due to the huge consumption of field measurements and the limitation of test conditions. Kozmar et al. $[10,11]$ used particle image velocimetry (PIV) to explore the shielding effect of the wind barrier and its influence on the flow field structure of the bridge, and optimized the height and porosity of the wind barrier. He et al. [12] studied the influence of the height and porosity of the wind barrier on the 
aerodynamic characteristics of the train on the viaduct based on the synchronous pressure measurement technique, and explained the aerodynamic mechanism of the wind barrier from the perspective of fluid mechanics. Zhang et al. [13] pointed out that setting up wind barriers can effectively improve the safety index of the train running on a bridge and greatly increase the critical wind speed for the running safety of the train. Deng et al. [14] investigated the influence of the wind barrier on aerodynamic coefficients, flow field structure, and running safety of the high-speed train in the bridge-tunnel section by using numerical simulation. Mohebbi et al. [15] researched the shielding effects of 15 wind barriers with different porosities on the train; their results showed that wind barriers can effectively reduce the aerodynamic coefficients of the train, and wind barriers with 15\% porosity had the best wind-proof effect. These studies mainly focused on the influence of the height and porosity of a single wind barrier on its wind protection effects, while there have been relatively few studies on the correlation between the structure type of wind barrier and its aerodynamic characteristics.

A wind barrier can significantly improve the running safety of a train, but it will increase the windward area of the bridge, disturb the flow field around the bridge, increase the turbulence effect, and adversely affect the wind resistance of the bridge. Buljac et al. [16] analyzed the influence of wind barriers on the aerodynamic and aeroelastic characteristics of three bridges with different cross-sections through wind tunnel tests, and pointed out that wind barriers increase the aerodynamic coefficients of the bridge and reduce the dynamic stability of the bridge deck. Guo et al. [17] discussed the influence of a wind barrier on the aerodynamic effect of the high-speed train-bridge system through experiments; their results revealed that a wind barrier can effectively reduce the drag and moment coefficients of a train, but it will increase the aerodynamic coefficients of the bridge.

There are various types of geometrical structures of wind barriers; most of the existing studies focus on the vertical wind barrier, although curved wind barriers are also commonly used in engineering. Zhou et al. [18] conducted numerical simulation studies on the decelerate effect on airflow of curved wind barriers with different porosities under various wind attack angles. They found that the wind protection effect of curved wind barrier shows a linear downward trend with the change of wind attack angle from negative to positive, and has an optimal porosity. Ogueta-Gutiérrez et al. [19] concluded that the curved barrier with solid screen can significantly reduce static loads of the train, but will increase bridge static loads, while adversely affecting the catenary above the railway line through a systematic experimental study. Compared with parameters such as porosity and height, curvature is also an important factor affecting the aerodynamic characteristics of curved wind barriers. However, there have been few studies on the aerodynamic performance of a curved wind barrier, especially on the curvature of a curved wind barrier. It is necessary to investigate the influence of curved wind barriers with different curvatures on the aerodynamic performance of a train-bridge system.

The aims of this paper are to investigate the influences of a curved wind barrier with different curvatures and different train-bridge combinations on crosswind aerodynamic characteristics of a train-bridge system, and provide a basis for setting a curvature wind barrier with a reasonable value. A streamlined flat box girder and a Metro A-type train are taken as background, and the delayed detached eddy simulation method (DDES) based on the shear stress transport $k-\omega$ (SST $k-\omega)$ turbulence model is adopted. The numerical model of a train-bridge system with a curved wind barrier is established. On the basis of verifying the accuracy of numerical simulation by wind tunnel tests, the influence of a wind barrier with four curvatures on the aerodynamic performance of a train-bridge system are investigated. The variations of the train's aerodynamic and wind pressure coefficients under different train-bridge combinations are also studied. The aerodynamic mechanism of curved wind barrier is revealed through analyzing the velocity streamline diagrams, wind profiles, pressure cloud diagrams, aerodynamic coefficients and the wind pressure distributions of a train that are obtained by numerical simulations. 


\section{Numerical Simulation}

\subsection{Geometric Model}

A streamlined flat box girder and a Metro A-type train are used as the geometric model for numerical simulation. The scale of the model is 1:40, and the specific size is shown in Figure 1a. Some details of the train and bridge, such as the tracks, wheels, and bogie, are ignored. The length, height, and width of the bridge model are $1000 \mathrm{~mm}, 73 \mathrm{~mm}$, and $490 \mathrm{~mm}$, respectively, while those of the train model are $1000 \mathrm{~mm}, 109 \mathrm{~mm}$, and $89 \mathrm{~mm}$, respectively.
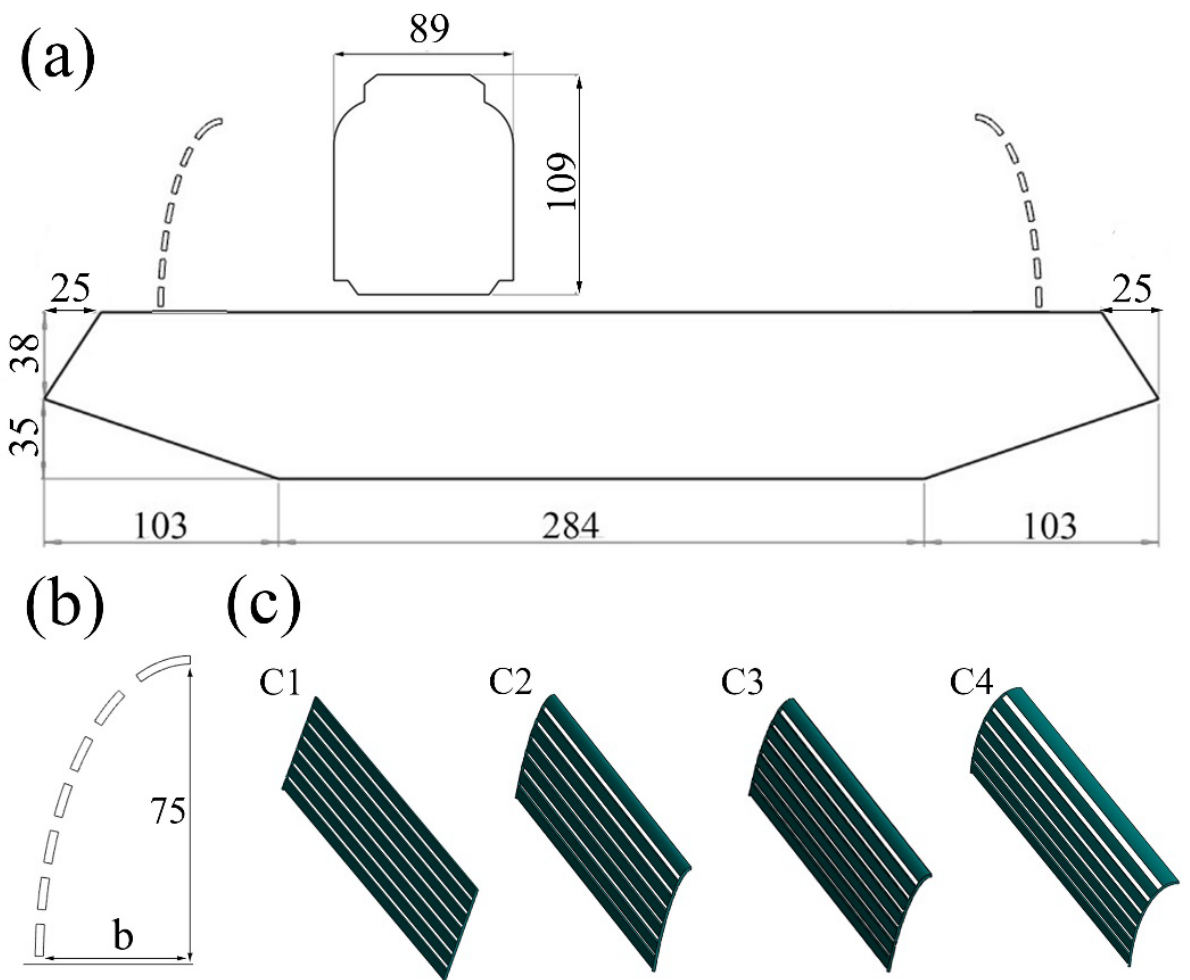

Figure 1. Scale models: (a) dimensions of the bridge and train models; (b) schematic of the curved wind barrier; (c) three-dimensional view of the curved wind barriers with four curvatures (unit: $\mathrm{mm}$ ).

The type of curved wind barrier is a common fence-type wind barrier, and the overall shape is a quarter ellipse. The porosity of the wind barrier is $\beta$. The length, height, and width of the wind barrier are $1000 \mathrm{~mm}, 75 \mathrm{~mm}$, and b, respectively, the curvature of the wind barrier is $\theta=b / 75$, as shown in Figure 1b. Figure 1c shows four different curved wind barriers, $\mathrm{C} 1, \mathrm{C} 2, \mathrm{C} 3$, and $\mathrm{C} 4$, with curvatures of $0,0.2,0.35$, and 0.5 , respectively. The curved wind barrier is composed of several horizontal baffles, and the curvature of each horizontal baffle is consistent with the wind barrier.

\subsection{Numerical Method}

Detached eddy simulation (DES) is a hybrid method of large eddy simulation (LES) and Reynolds average Navier-Stokes (RANS), RANS is employed to simulate near-wall flows, while LES is used to analyze flow separation in other regions. However, DES has very strict requirement on the quality of grids, and when the near-wall grids are not properly arranged, the boundary layers will be solved by RANS instead of LES, which would cause the modeled stress depletion (MSD) [20]. DDES is an improvement of DES that can improve the calculation efficiency and avoid the appearance of MSD.

The incompressible N-S equation is expressed as:

$$
\frac{\partial\left(u_{i}\right)}{\partial t}+\frac{\partial\left(u_{i} u_{j}\right)}{\partial x_{j}}=-\frac{\partial p}{\rho \partial x_{i}}+v \frac{\partial}{\partial x_{j}}\left(\frac{\partial u_{i}}{\partial x_{j}}\right)+f_{i}(i, j=1,2,3)
$$




$$
\frac{\partial u_{i}}{\partial x_{i}}=0
$$

where $u_{i}$ and $u_{j}$ are the components of velocity, $t$ is the time, $p$ is the pressure, $\rho$ is the density, $v$ is the kinematic viscosity, and $f_{i}$ is the body force of the $i$ direction.

The SST $k-\omega$ model can accurately simulate complex separation flows and is one of the most widely used turbulence models in engineering [21]. SST model formulations are as follows:

$$
\begin{gathered}
\frac{\partial(\rho k)}{\partial t}+\frac{\partial\left(\rho u_{j} k\right)}{\partial x_{j}}=\rho P-\beta^{*} \rho \omega k+\frac{\partial}{\partial x_{j}}\left[\left(\mu+\sigma_{k} u_{t}\right) \frac{\partial k}{\partial x_{j}}\right] \\
\frac{\partial(\rho \omega)}{\partial t}+\frac{\partial\left(\rho u_{j} \omega\right)}{\partial x_{j}}=\frac{\gamma}{v_{t}} P-\beta \rho \omega^{2}+\frac{\partial}{\partial x_{j}}\left[\left(\mu+\sigma_{\omega} u_{t}\right) \frac{\partial \omega}{\partial x_{j}}\right]+2\left(1-F_{1}\right) \frac{\rho \sigma \omega^{2}}{\omega} \bullet \frac{\partial k}{\partial x_{j}} \cdot \frac{\partial \omega}{\partial x_{j}} \\
F_{1}=\tanh \left\{\left\{\min \left[\max \left(\frac{\sqrt{k}}{\beta^{*} \omega y}, \frac{500 v}{y^{2} \omega}\right), \frac{4 \rho \sigma \omega^{2} k}{C D_{k \omega} y^{2}}\right]\right\}^{4}\right\}
\end{gathered}
$$

where $C D_{k \omega}=\max \left(2 \rho \sigma \omega^{2} \frac{1 \partial k \partial \omega}{\omega \partial x_{i} \partial x_{i}}, 10^{-10}\right)$ and $y$ is the distance nearest to the wall.

The turbulent eddy viscosity $v_{t}$ is defined as:

$$
v_{t}=\frac{a_{1} k}{\max \left(a_{1} \omega, S F_{2}\right)}
$$

where $S$ is an invariant measure of the strain rate and $F_{2}$ is the second blending function defined by:

$$
F_{2}=\tanh \left\{\left[\max \left(\frac{2 \sqrt{k}}{\beta^{*} \omega y}, \frac{500 v}{y^{2} \omega}\right)\right]^{2}\right\}
$$

where $\rho$ is the density, $u_{j}(j=1,2,3)$ represents the velocity components, $\mu$ is the laminar viscosity, and $\beta, \beta^{*}, \gamma, \sigma_{k}, \sigma_{\omega}, \sigma_{\omega^{2}}$, and $a_{1}$ are constants.

In order to simulate the flow field of unsteady and large separated flow around the train-bridge system with a curved wind barrier, the delayed detached eddy simulation (DDES) based on the shear stress transport (SST) $k-\omega$ turbulence model was adopted in this paper. The discretizations of the computational domain and the governing equations adopted the finite volume method. The commercial CFD software ANSYS FLUENT 19.2 with a pressure-based solver was used to perform all simulations of this study.

\subsection{Computational Domain and Grid Generation}

The computational domain of fluid simulation has a significant influence on the calculation results [22]. It is necessary to eliminate the interference of the computational domain boundary on the flow field around the segment model, and the turbulent wake needs to diverge completely. The computational domain and boundary conditions of a single train arranged on the windward side of the bridge are shown in Figure 2. The airflow inlet of the computational domain is velocity inlet, the wind attack angle is $\alpha$, and the outlet boundary condition is the zero pressure outlet. The front and rear walls are symmetrical boundaries, and the upper and lower walls are no-slip walls. The width of the bridge model is $B$ and the distance from the train-bridge system model to the inlet and outlet of the computational domain are $6 \mathrm{~B}$ and $13 \mathrm{~B}$, respectively. The distances from the upper and lower walls and front and rear walls of the model are both 6B.

The grid generation is completed in the commercial software ANSYS ICEM CFD. In order to make the simulation results more accurate, the strategy of hybrid grid and layered encryption is adopted to discrete the computational domain. The tetrahedral grid with better adaptability is used in the area close to the model of the train-bridge system with a wind barrier, and a fine area and extra-fine area are set around the model. The hexahedral grid is employed in the computing domain, except for the fine and extra-fine regions, which 
can improve the grid quality and computational efficiency. In order to accurately simulate the flow separation, 10 boundary layer grids are established on the model surface of bridge, train, and curved wind barrier, as shown in Figure 3a. The height of the first layer of the boundary layer grids is $0.029 \mathrm{~mm}$, which is calculated based on the dimensionless wall distance $\mathrm{y}^{+}=1$. The surface mesh of the model is shown in Figure $3 b$, the grid growth factor is set to 1.1, and the total number of grids varies with different wind barriers, but they all exceed 12 million. The grid quality is qualified after an assessment with ICEM CFD, which can guarantee the accuracy of the numerical simulation.

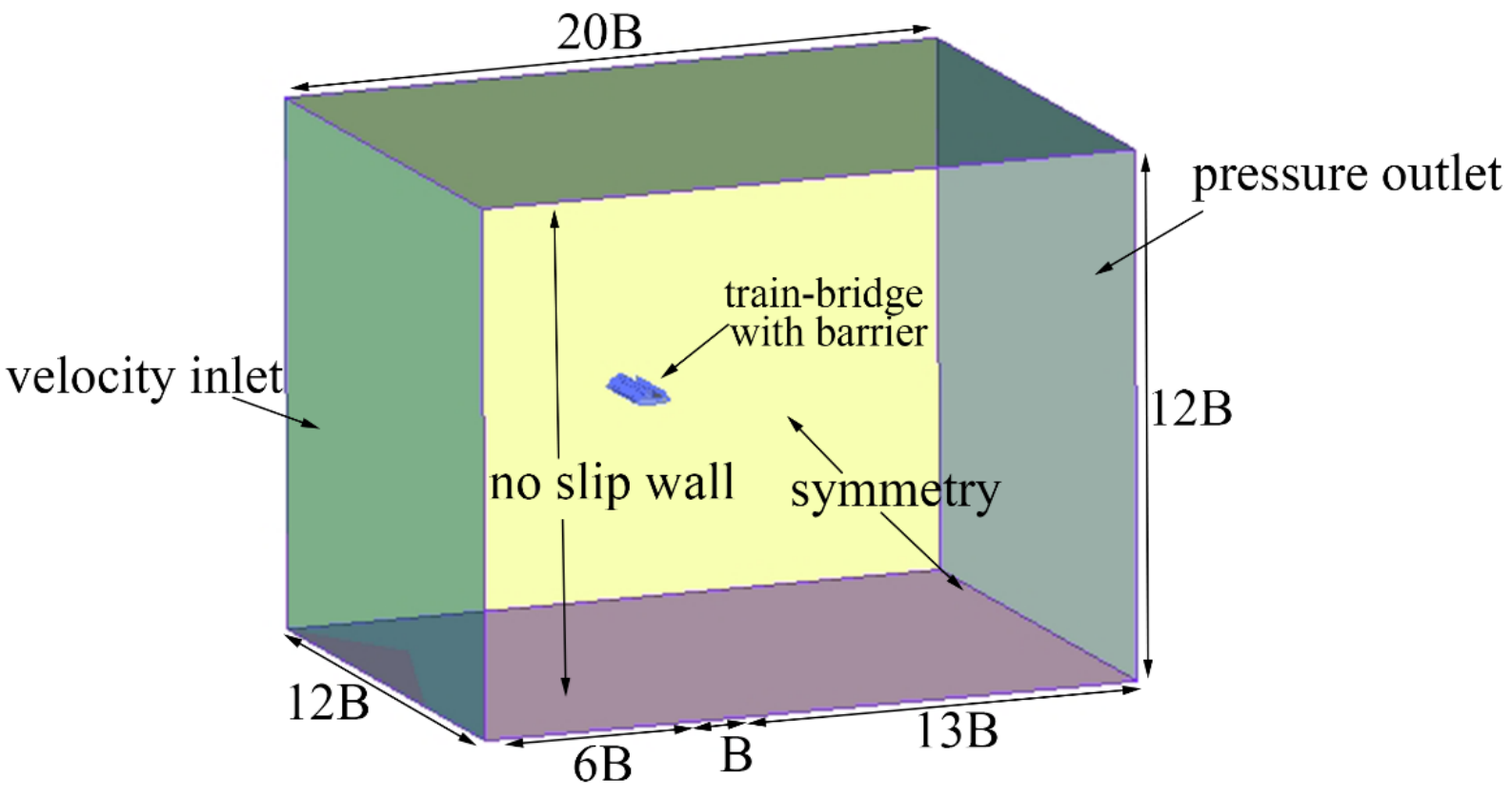

Figure 2. Computational domain and boundary conditions.

\subsection{Parameter Definition}

The three-component force coefficients are a set of non-dimensional parameters describing static wind load. It can be expressed in two ways: wind axis and body axis coordinate system, which can be converted to each other. In the wind axis coordinate system, the drag coefficient $C_{D}$, lift coefficient $C_{L}$, and moment coefficient $C_{M}$ are defined as follows:

$$
\begin{aligned}
C_{D} & =\frac{F_{D}}{0.5 \rho U_{0}^{2} H L} \\
C_{L} & =\frac{F_{L}}{0.5 \rho U_{0}^{2} B L} \\
C_{M} & =\frac{M}{0.5 \rho U_{0}^{2} B^{2} L}
\end{aligned}
$$

The wind pressure coefficient $C_{P}$ can be expressed as:

$$
C_{p}=\frac{P-P_{0}}{0.5 \rho U_{0}^{2}}
$$

where $F_{D}, F_{L}$, and $M$ are the drag, lift, and overturning moment of the model, respectively, the air density $\rho$ is $1.225 \mathrm{~kg} / \mathrm{m}^{3}$, the velocity of the airflow is $U_{0}=10 \mathrm{~m} / \mathrm{s}$, the length, height, and width of model are $L, H$, and $B$, respectively, $P$ is the static pressure on the surface of the model, and $P_{0}$ is the reference pressure. 


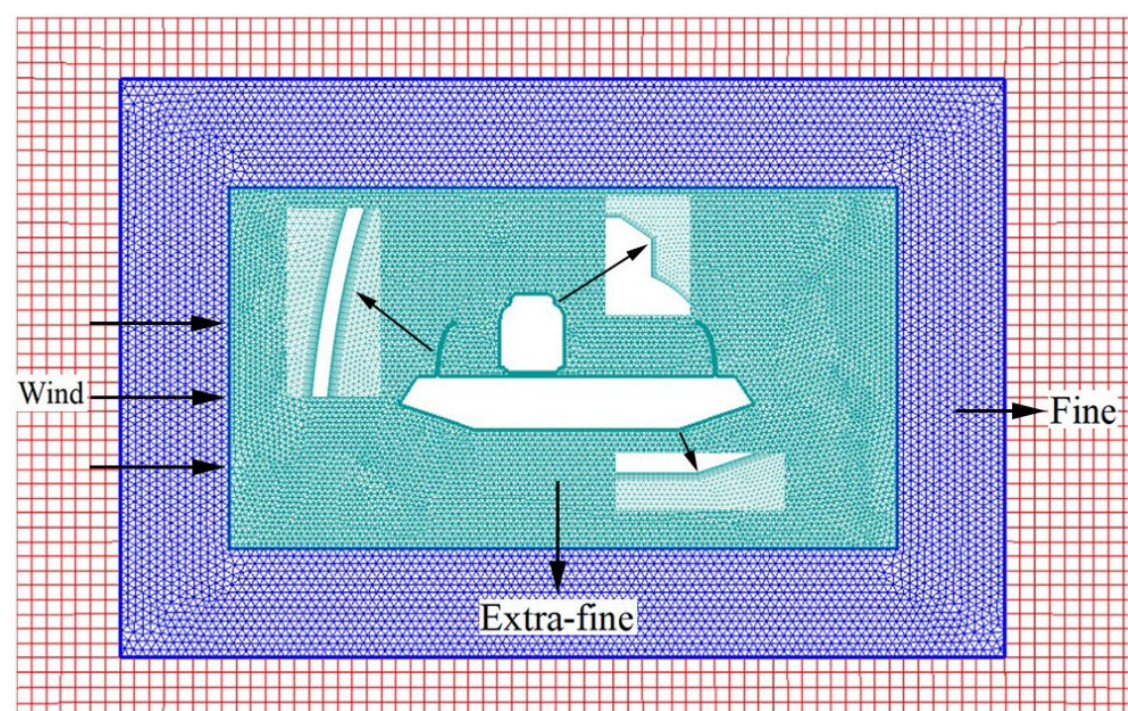

(a)

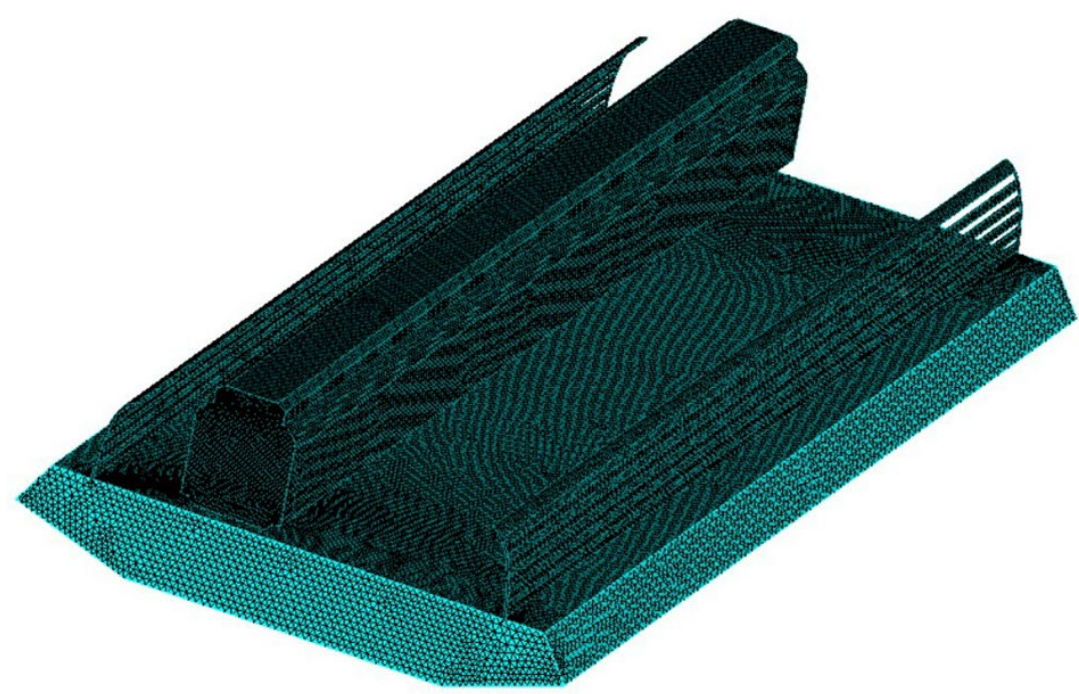

(b)

Figure 3. Schematic diagram of the computational mesh: (a) global view of the mesh, (b) surface mesh of the model.

\section{Validation of the Numerical Simulation}

The scaled 1:40 sectional model wind tunnel tests are carried out in the high-speed test section of the high-speed railway wind tunnel test system in Central South University, China. The test results are compared with the numerical simulation results to verify the accuracy of the numerical simulation. The schematic diagram of the wind tunnel and the high-speed test section are shown in Figure $4 \mathrm{a}, \mathrm{b}$. The dimensions of the high-speed test section are $15 \mathrm{~m} \times 3 \mathrm{~m} \times 3 \mathrm{~m}$ (length, width, and height). The oncoming flow velocity can be continuously adjusted within the range of $0-94 \mathrm{~m} / \mathrm{s}$. All tests in this study are conducted in a uniform flow field with a wind speed of $10 \mathrm{~m} / \mathrm{s}$, and the turbulence intensity is less than $0.5 \%$.

The aerodynamic forces of the train and bridge are tested after $\mathrm{C} 1$ wind barriers with respect to three different porosities $(0 \%, 20 \%$, and $40 \%)$, which were installed on both sides of the bridge. The geometric scale ratio of the model is 1:40, and the dimensions of the train, bridge, and wind barrier segment models are described in Section 2.1. The calculated 
maximum blockage ratio is $2.21 \%$, which meets the requirements of wind tunnel tests. In order to ensure the stiffness of segment models in the wind environment, as present in Figure 5a, the train, bridge, and wind barrier models are made of steel skeleton plastic, steel skeleton wood, and plastic materials, respectively. The wind tunnel test system is shown in Figure 5b. The IFS six-component dynamic balance used in these tests is produced by Japan's NITTA company with a force measurement resolution of $0.02 \mathrm{~N}$, a sampling frequency of $1 \mathrm{kHz}$, and a sampling duration of $30 \mathrm{~s}$. The aerodynamic force measured by the dynamic force balance can be converted by formulas (8)-(10) to obtain the aerodynamic three-component force coefficients of the train and bridge.

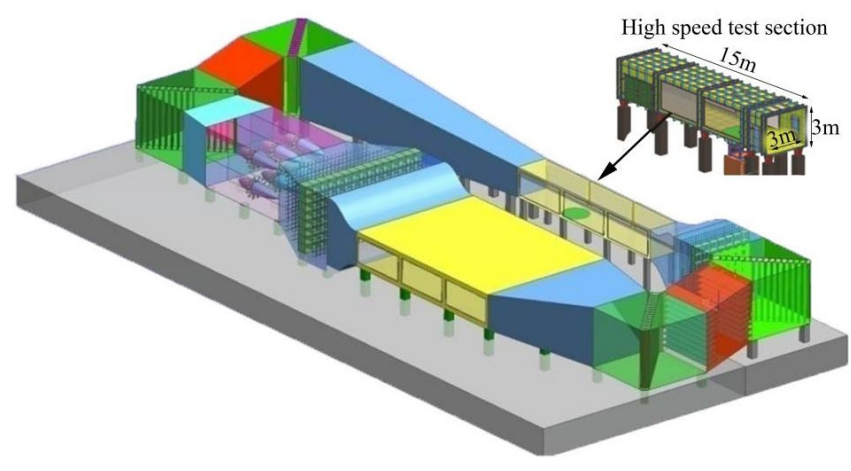

(a)

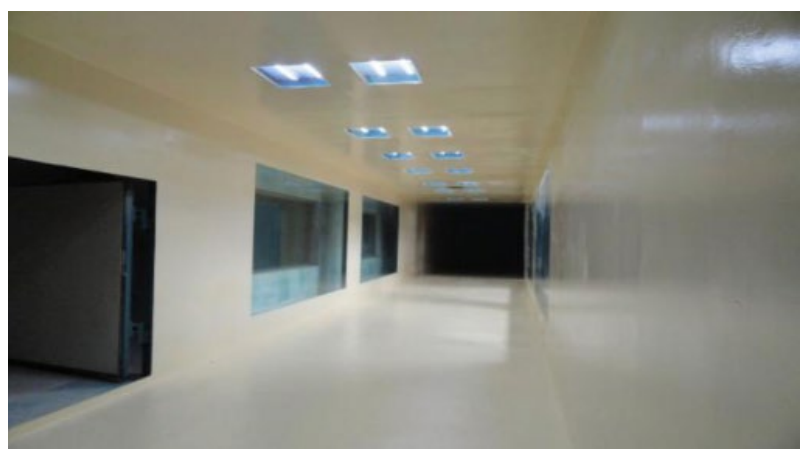

(b)

Figure 4. Schematic diagram of whole wind tunnel structure and high-speed test section: (a) schematic of the wind tunnel, (b) high-speed test section.

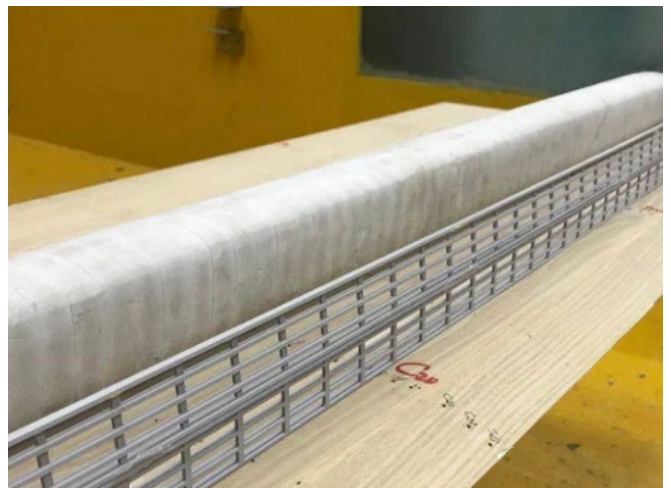

(a)

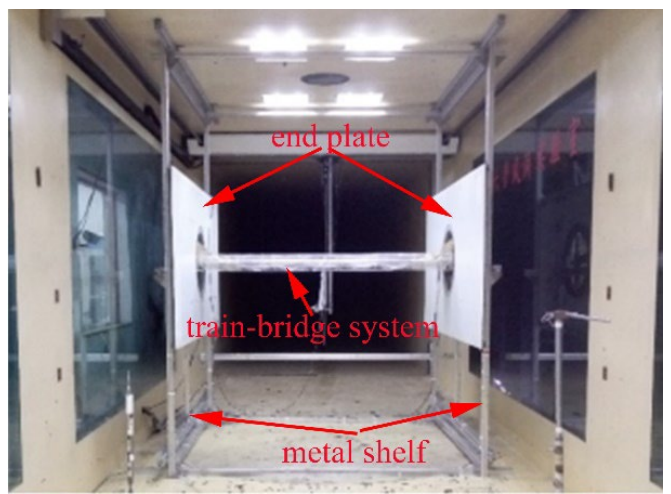

(b)

Figure 5. Wind tunnel test: (a) model of the train, bridge, and wind barrier, (b) wind tunnel test system.

The numerical models with the same geometric dimensions as the above-mentioned wind tunnel tests are established. The calculation conditions are consistent with the wind tunnel tests. The aerodynamic coefficients of the train and bridge after setting $\mathrm{C} 1$ wind barriers with three different porosities $(0 \%, 20 \%$, and $40 \%)$ on both sides of the bridge are simulated. The results of the wind tunnel tests and numerical simulations both show that with the gradual increase of the porosity of $\mathrm{C} 1$ wind barrier, the aerodynamic force of the train increases gradually, while the aerodynamic force of bridge decreases gradually. The two results are in good agreement and show consistent trends. The comparison of the wind tunnel tests and detailed numerical simulation results is presented in Table 1. It can be seen from Table 1 that the maximum error of the aerodynamic coefficients of the train and bridge obtained by wind tunnel tests and numerical simulations is less than $7 \%$. The errors are all within a reasonable range, which can verify the reliability of the numerical simulation. 
Table 1. Aerodynamic coefficients of the train and bridge model in wind tunnel tests and numerical simulations.

\begin{tabular}{|c|c|c|c|c|c|c|c|c|c|c|}
\hline \multicolumn{2}{|c|}{ Aerodynamic Coefficients } & \multicolumn{3}{|c|}{$C_{D}$} & \multicolumn{3}{|c|}{$C_{L}$} & \multicolumn{3}{|c|}{$C_{M}$} \\
\hline & Porosity & $0 \%$ & $20 \%$ & $40 \%$ & $0 \%$ & $20 \%$ & $40 \%$ & $0 \%$ & $20 \%$ & $40 \%$ \\
\hline \multirow{3}{*}{ Train } & Test & -0.098 & 0.252 & 0.629 & 0.126 & 0.186 & 0.249 & 0.381 & 0.597 & 0.793 \\
\hline & Numerical Simulation & -0.092 & 0.266 & 0.618 & 0.133 & 0.194 & 0.241 & 0.397 & 0.582 & 0.779 \\
\hline & Error $/ \%$ & 6.522 & 5.263 & 1.781 & 5.263 & 4.124 & 3.320 & 4.030 & 2.577 & 1.797 \\
\hline \multirow{3}{*}{ Bridge } & Test & 2.011 & 1.351 & 0.665 & -0.301 & -0.543 & -0.696 & 0.199 & 0.257 & 0.297 \\
\hline & Numerical Simulation & 1.906 & 1.367 & 0.701 & -0.314 & -0.567 & -0.684 & 0.203 & 0.264 & 0.288 \\
\hline & Error $/ \%$ & 5.509 & 1.170 & 5.136 & 4.140 & 4.233 & 1.754 & 1.970 & 2.652 & 3.125 \\
\hline
\end{tabular}

\section{Results and Discussion}

\subsection{The Influence of the Wind Barrier with Different Curvatures on the Aerodynamic} Characteristics of the Bridge

The effects of curved wind barriers with four curvatures on the aerodynamic performance of the bridge have been investigated in this section. The porosity of the curved wind barrier is $30 \%$, and the velocity of the horizontal airflow $U_{0}=10 \mathrm{~m} / \mathrm{s}$ (wind attack angle $\alpha=0^{\circ}$ ). The flow field, wind profile, wind pressure distribution, and aerodynamic coefficients of the bridge are given.

Figure 6 shows the mean velocity streamline diagram of the bridge deck without and with wind barriers. It can be seen from Figure 6a that the airflow separates at the wind fairing and accelerates at the leading point of the bridge without a wind barrier. The wind speed around the leading point can reach up to $13 \mathrm{~m} / \mathrm{s}$. The wind speed of the entire area above the bridge deck exceeds $10 \mathrm{~m} / \mathrm{s}$, which is a threat to the running safety of the train. After the curved wind barrier is set on the bridge, the acceleration area of the airflow moves to the top of the wind barrier. The greater the curvature, the better the diversion effect, and the higher the wind speed near the top of the wind barrier. Due to the shielding effect of the wind barrier, the wind speed around the bridge is significantly reduced. The wind barrier $\mathrm{C} 1$ has the best deceleration effect on the airflow, followed by the wind barrier $\mathrm{C} 3$, while the wind barriers $\mathrm{C} 2$ and $\mathrm{C} 4$ are worse. As the curvature increases, the wake height of the wind barrier decreases, indicating that the protection range becomes smaller.
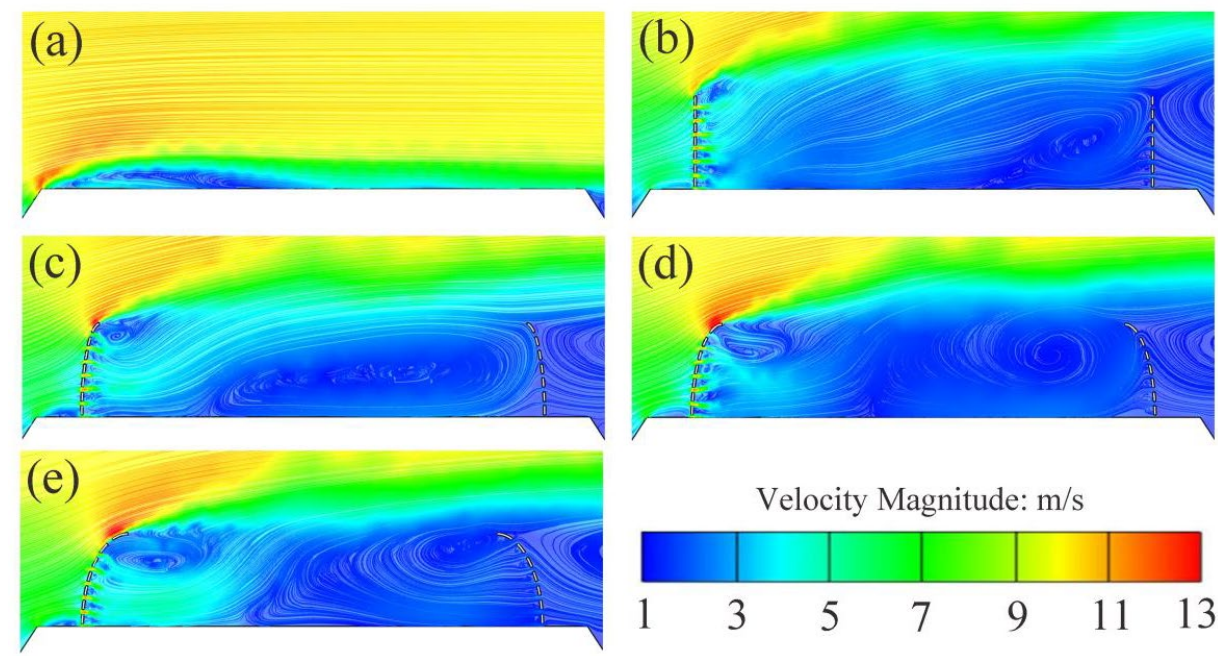

Figure 6. Mean velocity streamline diagram of the bridge deck: (a) without a wind barrier, (b) with the $\mathrm{C} 1$ wind barrier, (c) with the $\mathrm{C} 2$ wind barrier, (d) with the $\mathrm{C} 3$ wind barrier, (e) with the $\mathrm{C} 4$ wind barrier. 
The wind barrier changes the flow field of the bridge, and the airflow near the bridge deck becomes disordered. Two obvious vortices are generated at the bridge deck and the top of the wind barrier on the windward side of the bridge. The larger the vortex, the stronger the interference of the wind barrier to the flow field of the bridge. The vortex near the top of the wind barrier on the windward side of the bridge expands with the increase in curvature. The vortex close to the bridge deck is less affected by the curvature of the wind barrier, covering almost half of the bridge deck.

Figure 7 illustrates the wind profile at different positions behind the wind barrier on the windward side of the bridge, where the horizontal and vertical axes of the coordinate axis are normalized to the inflow wind speed and the vertical height of the wind barrier, respectively. $y$ is the vertical distance from the bridge deck, $H_{b}$ is the vertical height of the wind barrier, and $\mathrm{X}$ represents the horizontal distance between a certain place on the bridge deck and the wind barrier of the bridge's windward side. As can be seen from Figure 7, the curved wind barrier can significantly reduce the average wind speed in the area below a certain height of the bridge deck. Due to the interaction between the high-speed airflow accelerated at the top of the wind barrier and the low-speed airflow blocked through the wind barrier, there is an obvious velocity gradient in the vertical direction of the whole bridge deck. In the area below the height of the wind barrier on the bridge deck $\left(y / H_{b}<1\right)$, the deceleration effect of the curved wind barrier on the airflow is obvious, and the average wind speed at different positions behind the wind barrier does not exceed $3 \mathrm{~m} / \mathrm{s}$. After the height exceed the height wind barrier on the bridge deck $\left(1<y / H_{b}<1.5\right)$, the average wind speed increases rapidly with the increase of height. When the height exceeds 1.5 times of the wind barrier's height $\left(y / H_{b}>1.5\right)$, the deceleration effect of the wind barrier on the airflow disappears, and the average wind speed has exceeded the incoming flow.

It can be seen from Figure $7 \mathrm{a}$ that the closer to the wind barrier on the windward side of the bridge, the higher the average wind speed, which changes more sharply in the vertical direction. As shown in Figure $7 \mathrm{~b}-\mathrm{f}$, the greater the increase of the distance from the wind barrier on the windward side of the bridge, the stronger the inhibitory effect of the wind barrier on the airflow. The airflow tends to be stable and the average wind speed decreases, which is consistent with the previous results from Telenta et al. [23]. Compared with the three other curved wind barriers, the average wind speed at different positions behind the $\mathrm{C} 4$ wind barrier are larger. This indicates that the curvature of the curved wind barrier exceeds a certain value, and the deceleration effect on the airflow will be significantly weakened.

Figure 8 shows the pressure cloud diagram of the bridge without and with wind barriers. As shown in Figure 8a, the airflow separates at the wind fairing and flows to the upper and lower surfaces of the bridge when no wind barrier is installed on the bridge. The upward airflow forms a small range of high wind pressure area near the wind fairing. Except for the negative pressure area around the leading point of the windward side, the wind pressure on the upper surface of the whole bridge deck is close to $0 \mathrm{~Pa}$. The pressure of the entire region under the bridge is negative due to the downward airflow and forms high negative pressure areas at two inflection points on the lower surface of bridge. After the curved wind barrier is installed on the bridge deck, as present in Figure 8b-e, the high wind pressure area near the wind fairing spreads to the windward side of the wind barrier. Due to the blocking effect of the wind barrier, the pressure of whole area above the bridge deck becomes negative. A high negative pressure area is also formed under the wind fairing, and the range and negative pressure at two inflection points on the lower surface of the bridge increase. The curvature of the wind barrier has great influence on the wind pressure distribution of the bridge. With the increase of the curvature of the wind barrier, the high-pressure region and pressure value between the wind fairing and the wind barrier on the windward side of the bridge decrease, and the high negative pressure area at the inflection point on the lower surface of the bridge also decreases slightly. 


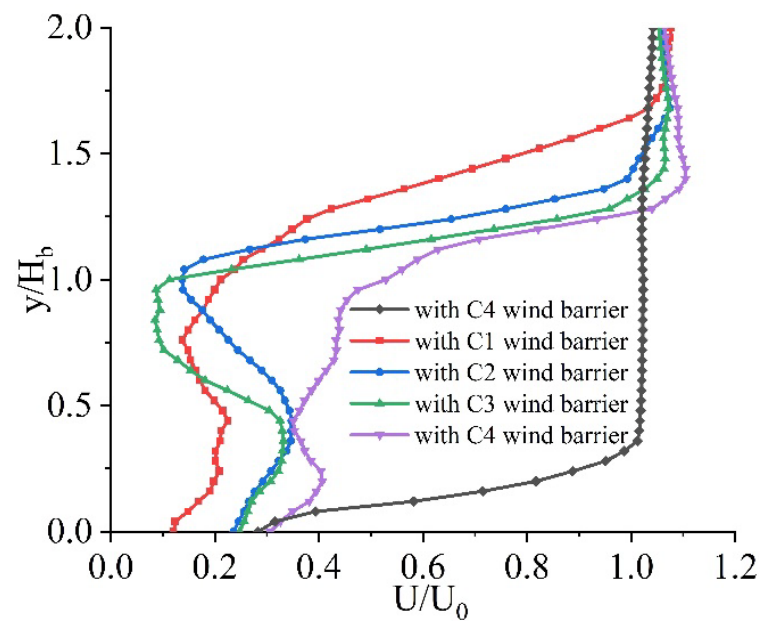

(a)

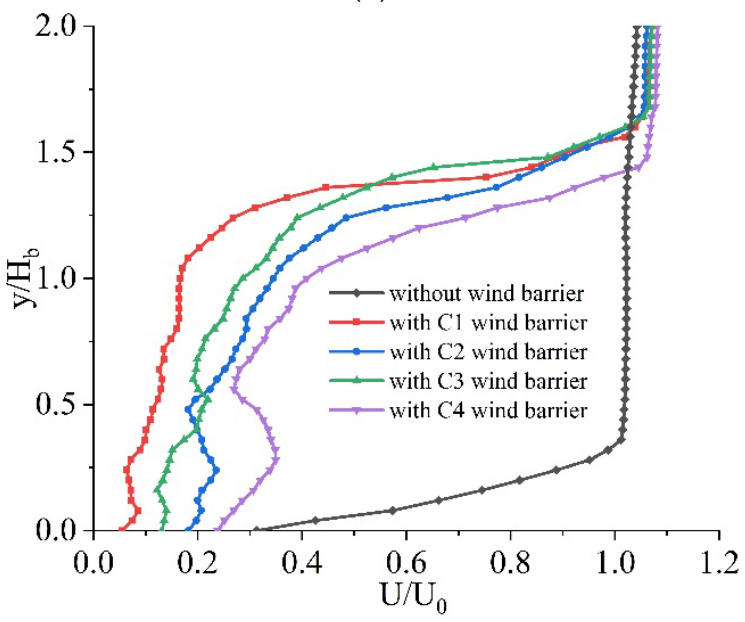

(c)

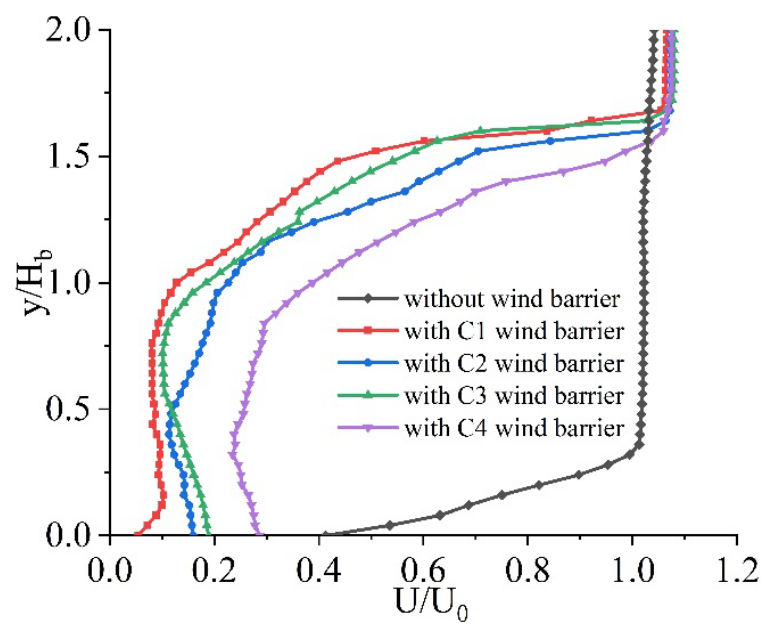

(e)

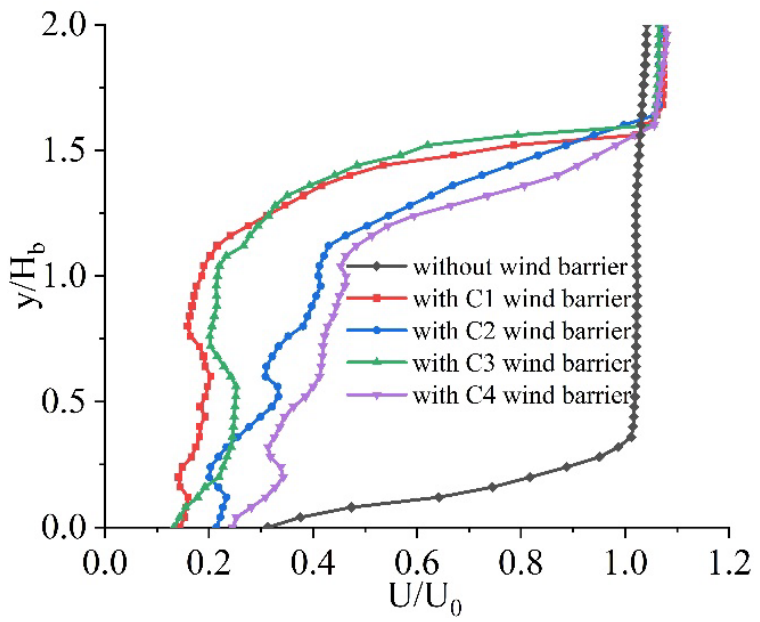

(b)

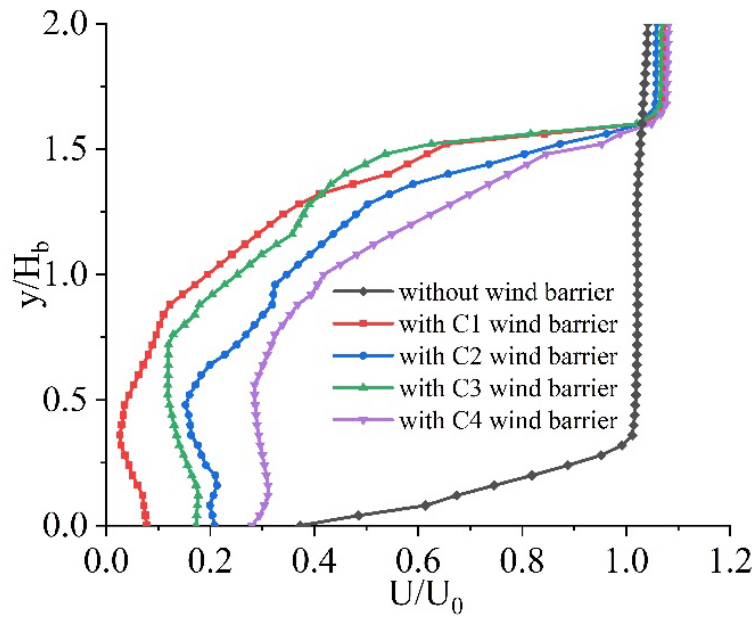

(d)

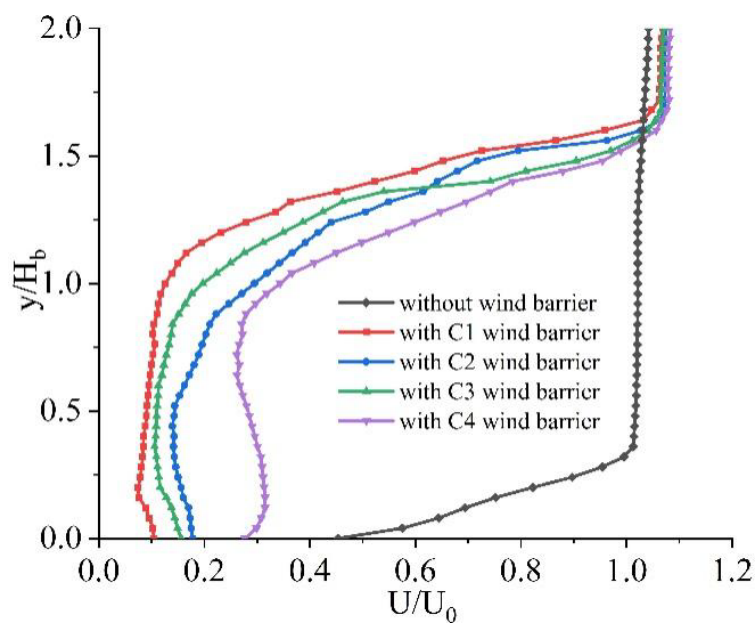

(f)

Figure 7. Mean velocity profiles at different positions behind the curved wind barrier on the windward side of the bridge: (a) $\mathrm{X}=H_{b}$, (b) $\mathrm{X}=1.5 H_{b},(\mathbf{c}) \mathrm{X}=2 \mathrm{H}_{b},(\mathbf{d}) \mathrm{X}=2.5 H_{b},(\mathbf{e}) \mathrm{X}=3 H_{b},(\mathbf{f}) \mathrm{X}=3.5 H_{b}$. 


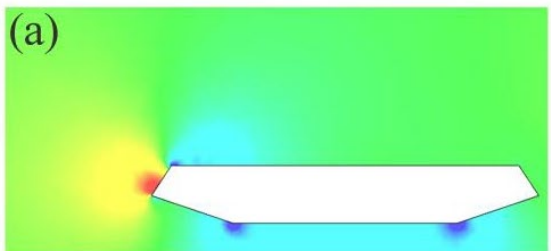

(c)

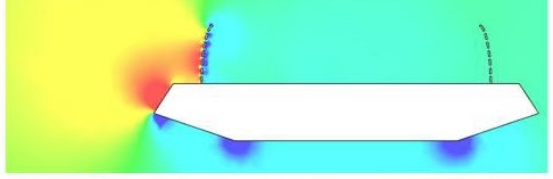

(e)

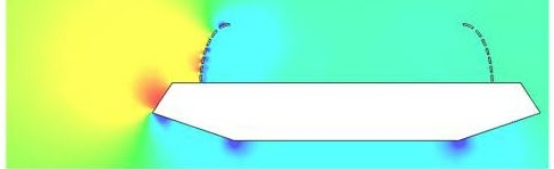

(b)

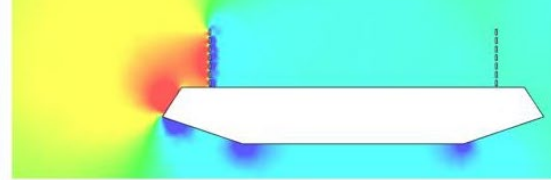

(d)

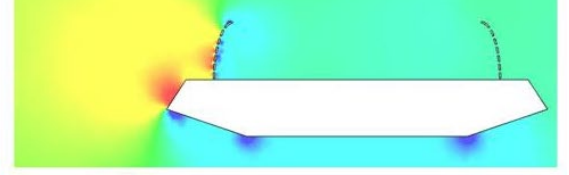

Pressure: $\mathrm{Pa}$

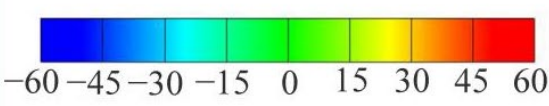

Figure 8. Pressure cloud diagram of the bridge: (a) without a wind barrier, (b) with the $\mathrm{C} 1$ wind barrier, (c) with the C2 wind barrier, (d) with the C3 wind barrier, (e) with the C4 wind barrier.

Figure 9 presents the variations of drag and lift coefficients of the bridge without and with wind barriers. The wind load on the wind barrier will transmit to bridge, and the aerodynamic coefficients of the bridge increase. It can be seen from Figure $9 a, b$ that the aerodynamic coefficients of bridge decreases with the increase of the wind barrier's curvature, especially drag coefficient $C_{D}$. The $C_{D}$ value of the bridge without a wind barrier is 0.457 ; after $\mathrm{C} 1, \mathrm{C} 2, \mathrm{C} 3$, and $\mathrm{C} 4$ wind barriers are installed on the bridge, the $C_{D}$ values of the bridge are $0.761,0.668,0.626$, and 0.601 , increasing $66.5 \%, 46.2 \%, 36.9 \%$, and $31.5 \%$, respectively. This indicates that the smaller the curvature of the wind barrier, the stronger the blocking effect on the airflow, and the greater the wind load on the bridge. Compared with the other three curved wind barriers, the installation of the $\mathrm{C} 1$ wind barrier significantly increases the drag and lift coefficients of the bridge, which has a more negative influence on the safety of the bridge. The increase of the wind barrier's curvature can decrease the aerodynamic coefficients of the bridge due to the decreased blocking effect of the wind barrier.

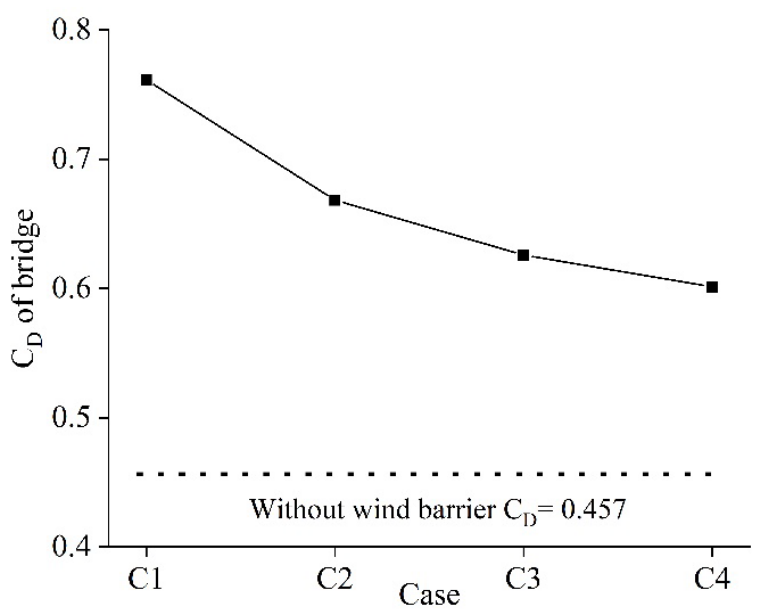

(a)

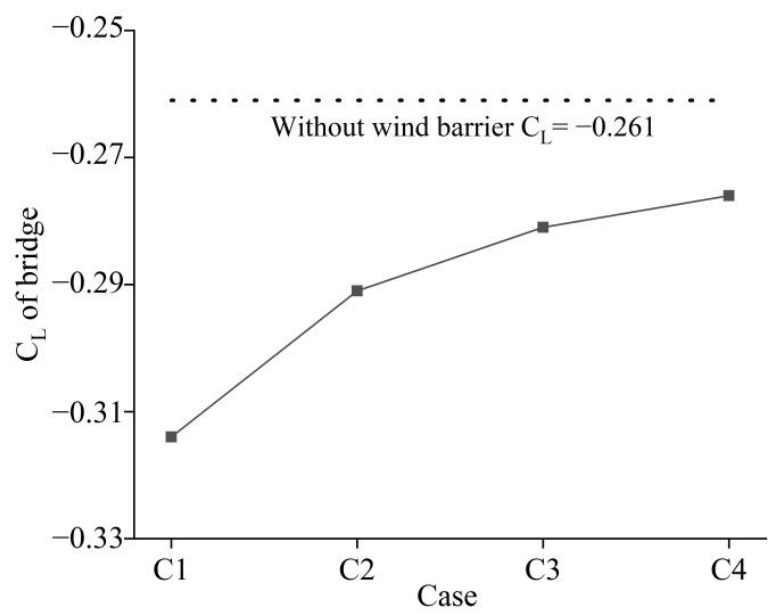

(b)

Figure 9. Aerodynamic coefficients of the bridge with different curved wind barriers: (a) drag coefficients of the bridge, (b) lift coefficients of the bridge. 


\subsection{Effects of the Curved Wind Barrier on the Aerodynamic Characteristics of the Train-Bridge System}

The influence of curved wind barriers with four curvatures on the aerodynamic characteristics of the train-bridge system have been investigated under an incoming flow $U_{0}=10 \mathrm{~m} / \mathrm{s}$. The train is arranged on the windward side of the bridge, and the porosity of the wind barrier is 30\%. The pressure distribution, velocity field, and wind pressure coefficients of the train-bridge system with wind barriers of four curvatures are compared, and the variations of aerodynamic coefficients of the train and bridge under different wind attack angle are also concerned.

Figure 10 shows the effects of different curved wind barriers on the pressure distribution of the train-bridge system (wind attack angle $\alpha=0^{\circ}$ ). It can be seen from Figure 10a-e that the wind pressure on the windward surface of the train drops significantly for the wind barrier installed on the bridge, and the blocking effect of the curved wind barrier on the airflow weakens as the curvature increases. The maximum wind pressure on the windward surface of the train is $8.86 \mathrm{~Pa}$ with the installation of the $\mathrm{C} 1$ wind barrier, while when the $\mathrm{C} 4$ wind barrier is installed on the bridge, the maximum wind pressure on the windward surface of the train is $24.97 \mathrm{~Pa}$. Similar to when there is no train on the bridge, the high wind pressure area and wind pressure value between the wind fairing and the wind barrier on windward side of the bridge decrease with the increase of curvature, and the negative pressure area under the bridge is less affected by the wind barrier.
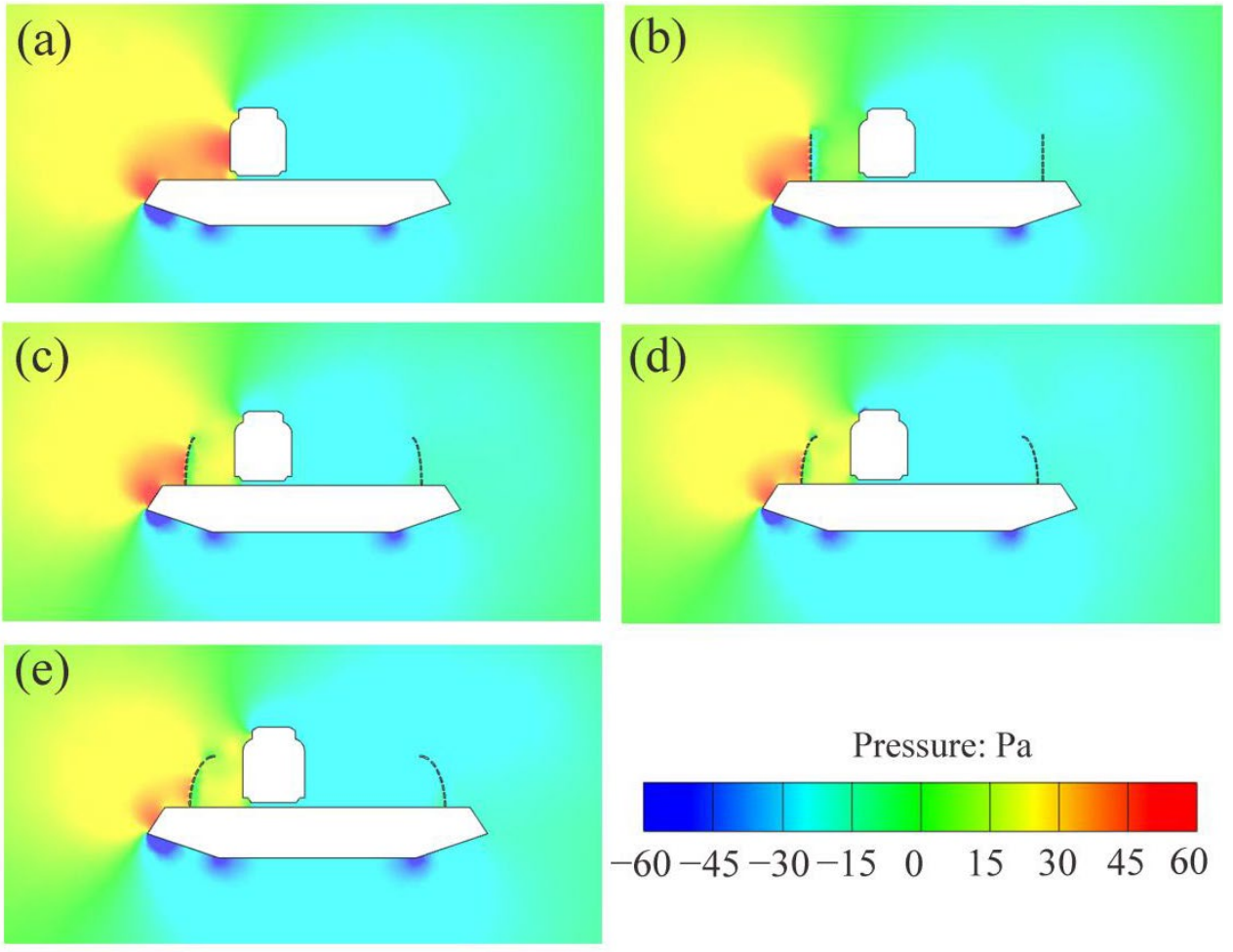

Figure 10. Pressure contours of the train-bridge system: (a) without a wind barrier, (b) with the $\mathrm{C} 1$ wind barrier, (c) with the $\mathrm{C} 2$ wind barrier, (d) with the $\mathrm{C} 3$ wind barrier, (e) with the $\mathrm{C} 4$ wind barrier.

Figure 11 presents pressure taps on the section of the train, and pressure coefficients of the train's section in respect of different curved wind barriers (wind attack angle $\alpha=0^{\circ}$ ). A total of 34 pressure taps are evenly arranged on the train's section, as shown in Figure 11a. It can be seen from Figure $11 \mathrm{~b}$ that without the installation of wind barriers on the bridge, the wind pressures at all pressure taps on the windward surface of the train are positive, while wind pressures on the roof, bottom, and leeward surface of the train are all negative. The negative pressure of point 11 is the largest, followed by point 12 , which shows that the airflow is separated near these two points. After the curved wind barrier is installed 
on the bridge, the positive pressures on the windward surface of the train are significantly decreased due to the suppression effect of the wind barrier on the airflow, and the wind pressures at some points even change from positive to negative. The negative pressure on the roof of train decreases, while the wind pressures on the bottom and leeward surface change slightly. The negative pressure at point 11 is significantly reduced, and the pressure at point 12 becomes the maximum negative pressure. The wind pressures on the windward surface of the train increase with the curvature increases, and hardly fluctuate in the vertical direction. The pressure on the bottom and leeward surface of the train is less affected by the wind barrier, which is consistent with existing results by $\mathrm{Gu}$ et al. [9] and He et al. [12].

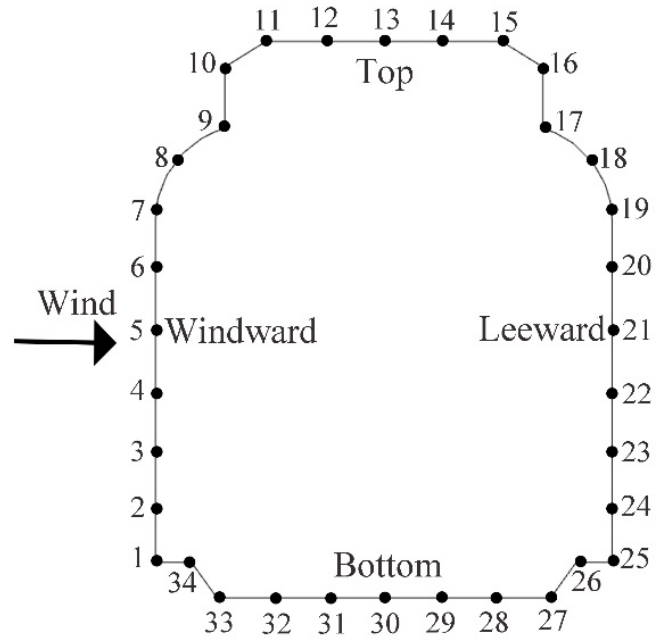

(a)

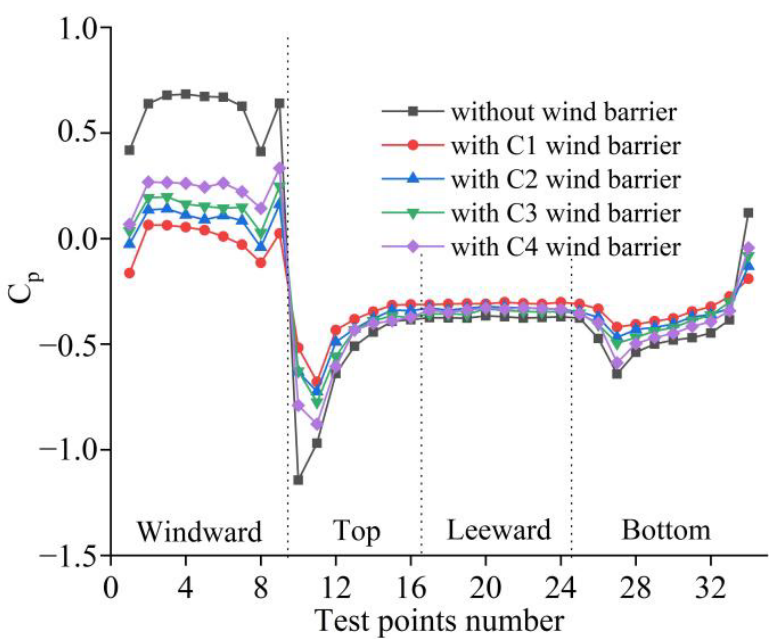

(b)

Figure 11. Schematic diagram of pressure taps on the train and pressure coefficients of the train with different curved wind barriers: (a) pressure taps on the train's section, (b) pressure coefficients of the train's surface.

Figure 12 shows the velocity streamline of the train-bridge system without and with wind barriers (wind attack angle $\alpha=0^{\circ}$ ). As shown in Figure 12a, for the bridge without a wind barrier, the wind speeds at the bottom and roof of the train are about $9 \mathrm{~m} / \mathrm{s}$ and $11 \mathrm{~m} / \mathrm{s}$, respectively, which can adversely affect the safety of the train. It can be seen from Figure $12 \mathrm{~b}-\mathrm{e}$ that with the installation of the wind barrier on the bridge, the entire running area of the train is completely immersed in the wake of the wind barrier, and the wind speed decreases significantly. The curvature of the curved wind barrier has an important impact on the deceleration effects of the airflow. Compared with the $\mathrm{C} 2$ and $\mathrm{C} 4$ wind barriers, the wind speed in the train's running area is lower after the $\mathrm{C} 1$ and $\mathrm{C} 3$ wind barriers are installed on the bridge. Moreover, the airflow accelerates at the top of the curved wind barrier on windward side of the bridge, resulting in increased wind speed near the left roof of the train. The greater the curvature of the curved wind barrier, the stronger the airflow acceleration effects. Consequently, the wind barriers disturb the flow field of the train-bridge system, and the vortices are formed between the train and the curved wind barrier, which will be detrimental to the stability of the train. As the curvature of the wind barrier increases, the vortex near the back of the wind barrier on the windward side of the bridge gradually increases.

Figure 13 illustrates the variations of aerodynamic coefficients of the train and bridge with various wind attack angles for the wind barriers with four curvatures. It can be seen from Figure 13a-c that the aerodynamic coefficients of the train decrease with the increase of the wind attack angle from negative to positive. This is because the shielding effect of the bridge is enhanced when the wind attack angle increases, and more incoming flow is blocked by the front edge of the bridge, resulting in the reduction of airflow acting on the train. After the wind attack angle exceeds $4^{\circ}$, the blocking effect of the bridge 
hardly increases and the aerodynamic coefficients of the train tend to be stable. In contrary to the train, as shown in Figure $13 \mathrm{~d}-\mathrm{f}$, the aerodynamic coefficients of bridge increase approximately linearly with the increases of wind attack angle. In particular, the increase in the aerodynamic coefficients of the bridge is more emphasized in the range of positive wind attack angles.
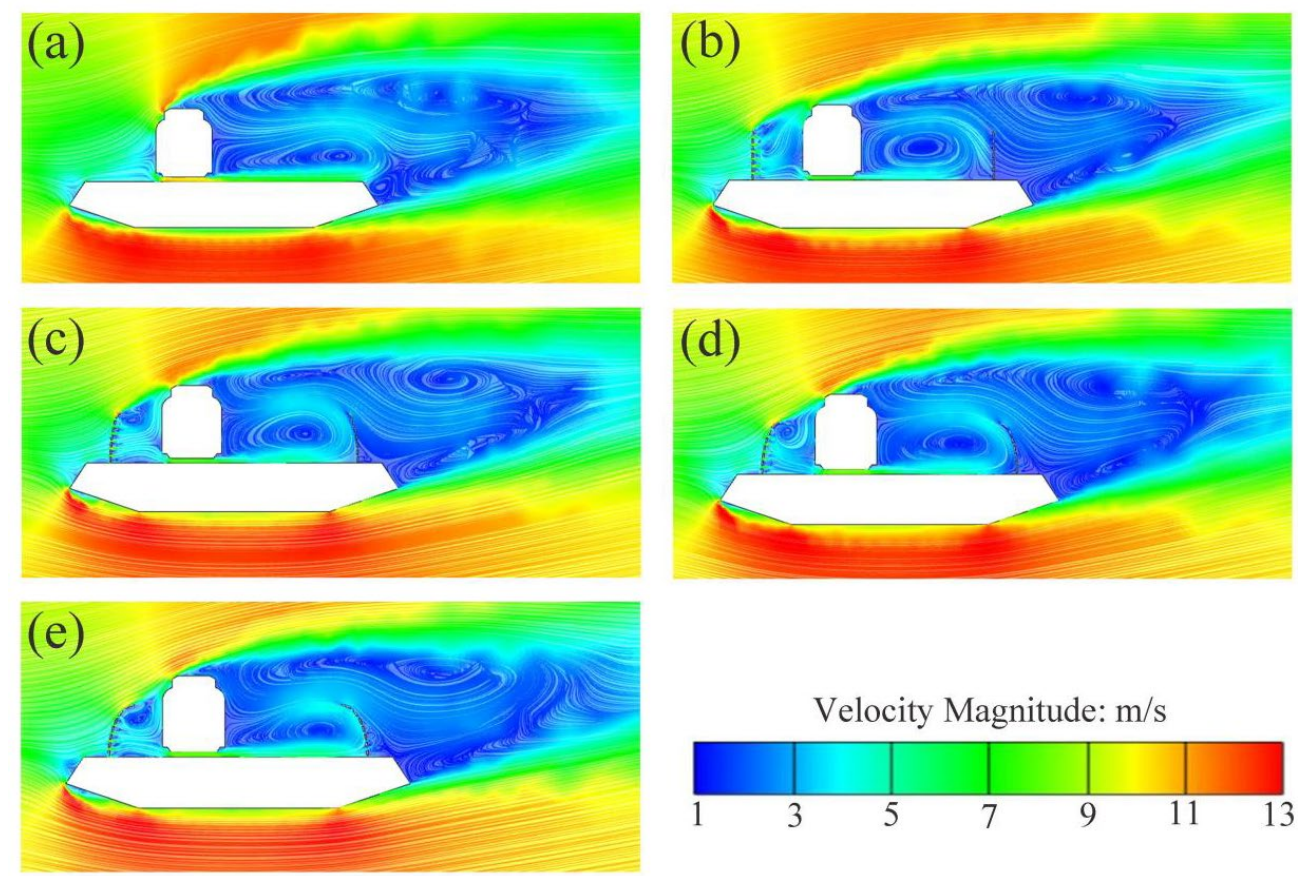

Figure 12. Velocity streamline of the train-bridge system: (a) without a wind barrier, (b) with the $\mathrm{C} 1$ wind barrier, (c) with the $\mathrm{C} 2$ wind barrier, (d) with the $\mathrm{C} 3$ wind barrier, (e) with the $\mathrm{C} 4$ wind barrier.

The curvature of the wind barrier has a significant impact on the aerodynamic coefficients of the train-bridge system. As the curvature of the wind barrier increases, the aerodynamic coefficients of the train increase, while the aerodynamic coefficients of the bridge decrease. With the installation of $\mathrm{C} 1$ wind barrier, the aerodynamic coefficients of the train can be best reduced, but those of the bridge are greatly increased. After setting the $\mathrm{C} 4$ wind barrier on the bridge, the aerodynamic coefficients of the bridge are relatively small; however, the train's drag and moment coefficients cannot be effectively reduced. Compared with the $\mathrm{C} 1$ and $\mathrm{C} 4$ wind barriers, the $\mathrm{C} 2$ and $\mathrm{C} 3$ wind barriers effectively reduce the aerodynamic force of the train and have less impact on the wind resistance of the bridge.

C2 and C3 wind barriers have similar performance in reducing aerodynamic force of the train, while the wind load that the $\mathrm{C} 2$ wind barrier adds to the bridge is significantly higher than that of the $\mathrm{C} 3$ wind barrier. Above all, the $\mathrm{C} 3$ wind barrier with curvature of 0.35 is more suitable for the safety protection of the train-bridge system in the present study.

\subsection{Influence of Curved Wind Barrier on the Aerodynamic Characteristics of the Train with Different Train-Bridge Combinations}

When the train is on the bridge, the train and the bridge form a train-bridge combination. There are three different train-bridge combinations in this paper: (1) one train on the track of the windward side of the bridge; (2) one train on the track of the leeward side of the bridge; and (3) two trains on both tracks of the bridge.

On the basis of the above research, after $\mathrm{C} 3$ wind barriers with different porosities are installed on the bridge (wind attack angle $\alpha=0^{\circ}$ ), the variations of aerodynamic threecomponent coefficients of the train and pressure coefficients of the train's section under different train-bridge combinations are compared. There are four cases for the tested train 
in three different train-bridge combinations; the schematic diagrams of the four cases are shown in Table 2.

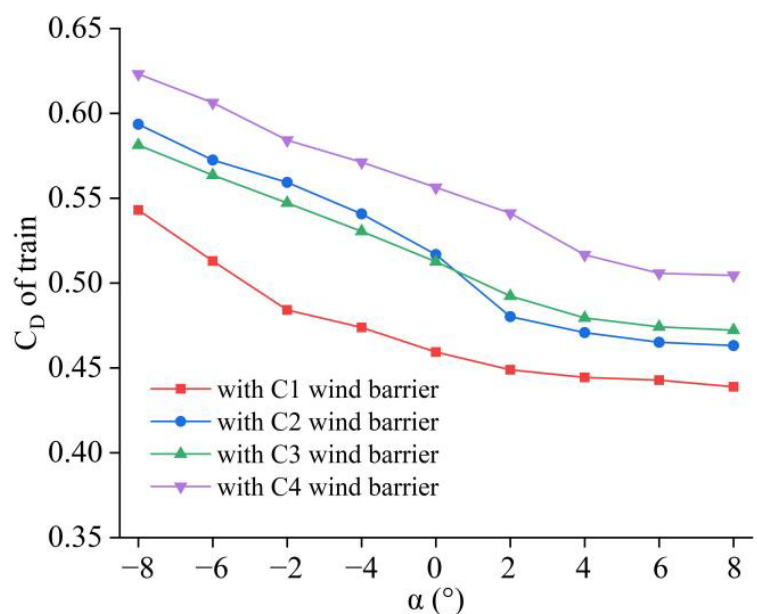

(a)

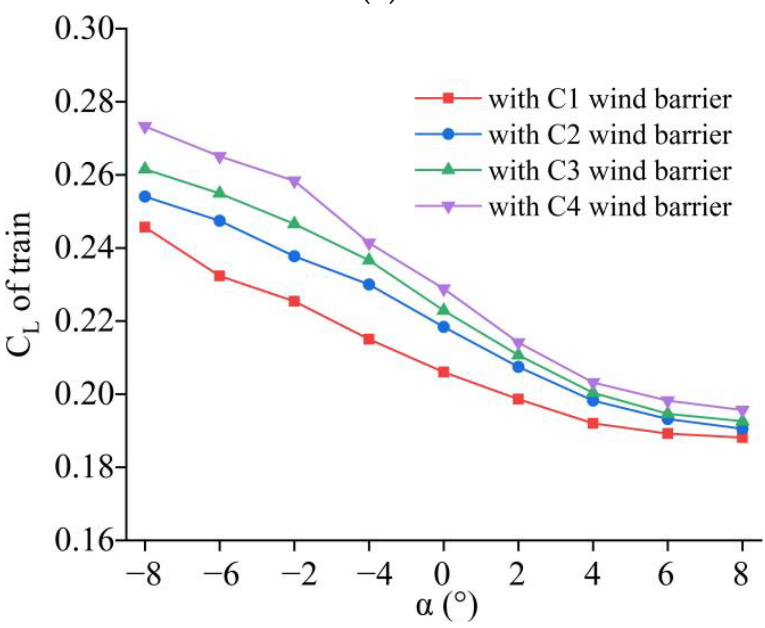

(c)

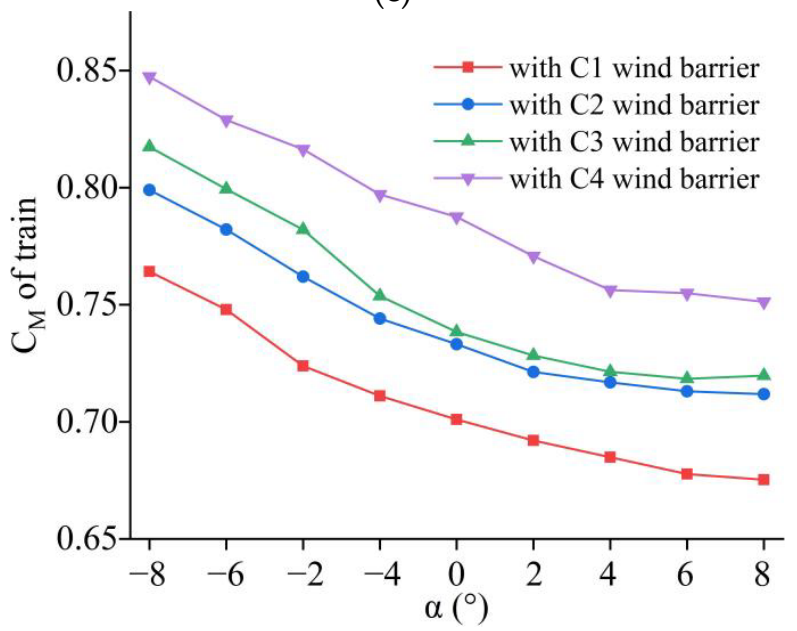

(e)

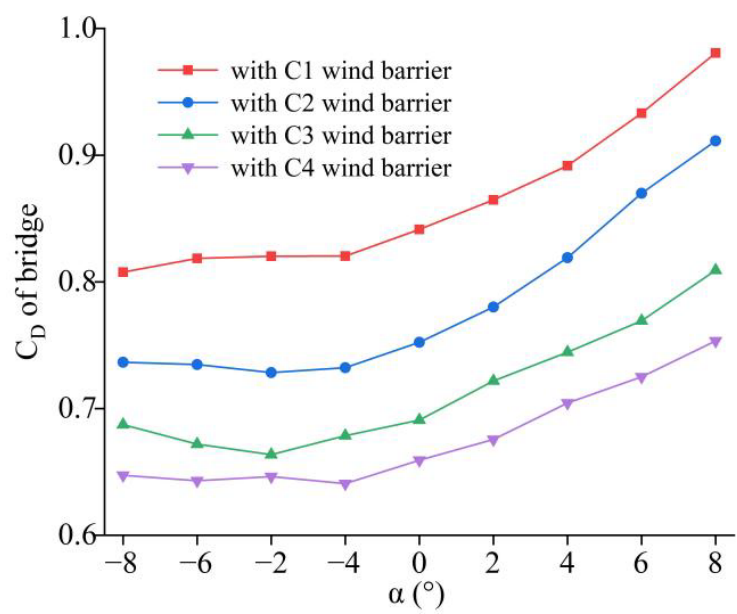

(b)

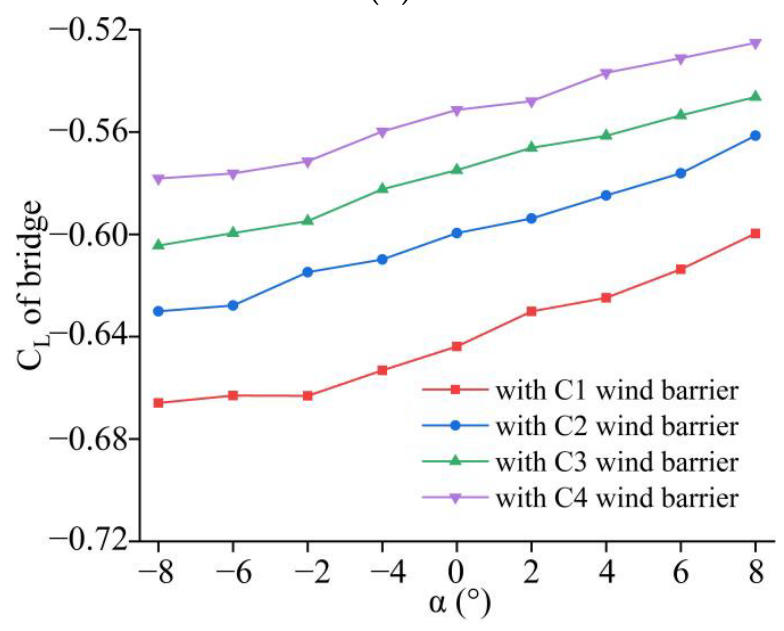

(d)

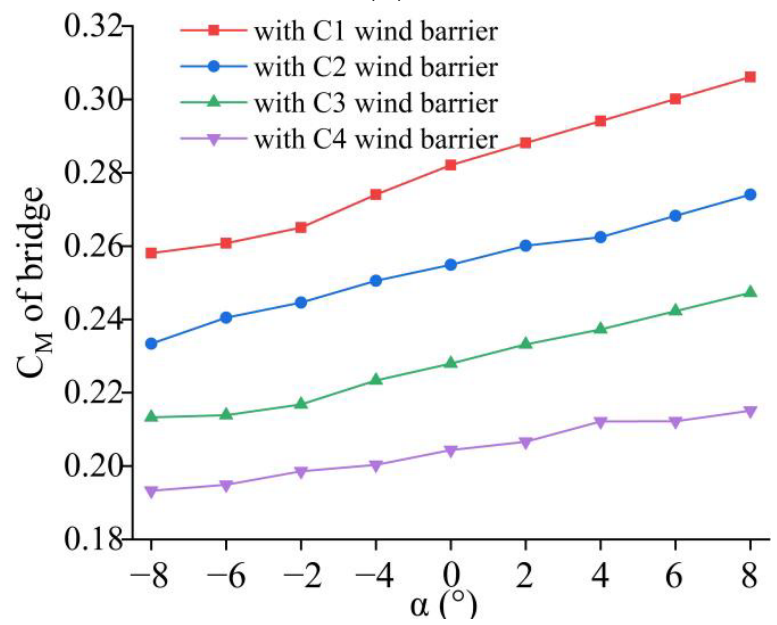

(f)

Figure 13. Aerodynamic coefficients of the train and bridge with different curved wind barriers: (a) drag coefficient of the train, (b) drag coefficient of the bridge, (c) lift coefficient of the train, (d) lift coefficient of the bridge, (e) moment coefficient of the train, and (f) moment coefficient of the bridge. 
Table 2. Schematic diagrams of the four cases for the tested train.

Case
Case2
Case3
Case4

Figure 14a-c presents the variations of aerodynamic three-component force coefficients of the train with the porosity of the wind barrier under different train-bridge combinations. The three-component coefficients of the train increase with the increase of the wind barrier's porosity. When there is only one train on the bridge, the test train of Case2 is in the lowspeed wake generated by the front edge of the bridge and the wind barrier of windward side, and the aerodynamic coefficients of the test train in Case 2 is significantly smaller than Case1. When there are trains on both the windward and leeward sides of the bridge, the train on the leeward side of the bridge will cause aerodynamic interference to the train on the windward side. The negative pressure on the leeward surface of the train on the windward side of the bridge will decrease slightly, resulting in the aerodynamic coefficients of the test train in Case3 to be slightly lower than Case1. The test train of Case4 is completely immersed in the wake of the curved wind barrier and the train on the windward side of the bridge. The aerodynamic coefficients are very small, especially the drag coefficient, which is a negative value close to 0 . With the increase of the porosity of the curved wind barrier, the drag coefficient slightly increases, but it is still negative.

Figure 15 shows the influence of $\mathrm{C} 3$ wind barriers with different porosities on the wind pressure distribution on the train's section (the pressure taps on the section of the train are shown in Figure 11a). When there is only one test train on the bridge (Case1, Case2), as present in Figure 15a,b, with the increase of the porosity of wind barrier, the wind pressure on the windward surface of the test train gradually increases from negative to positive, and the distribution along the vertical direction is hardly changed. Under the same test conditions, the positive pressure on the windward side and the negative pressure on the roof of the test train in Case1 are significantly greater than those in the test train in Case2, and the wind pressure on the leeward surface and bottom of the test train under the two cases are almost the same. This can explain the reason why the aerodynamic coefficients of the test train of Case1 are significantly greater than that of the test train of Case2, as shown in Figure 14. 


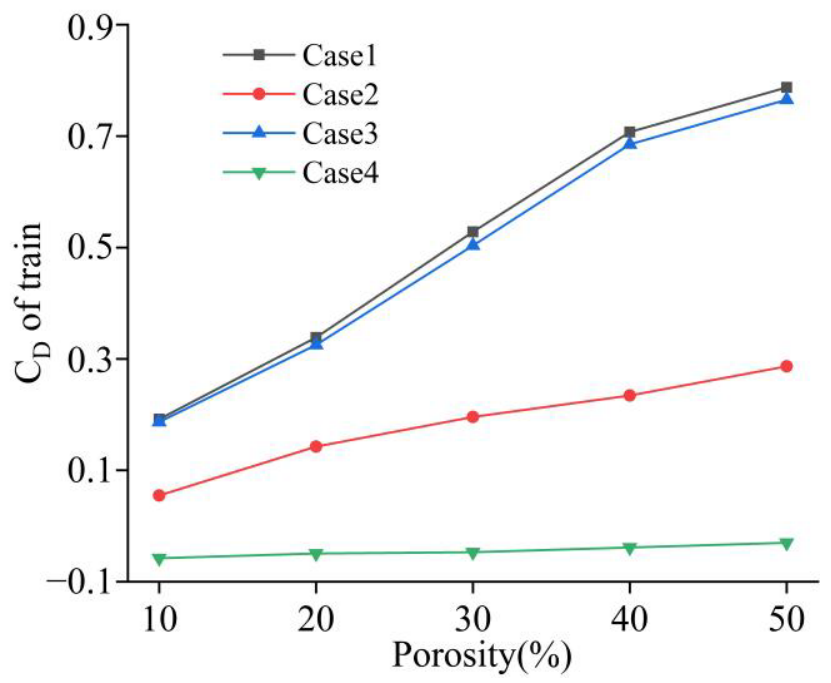

(a)

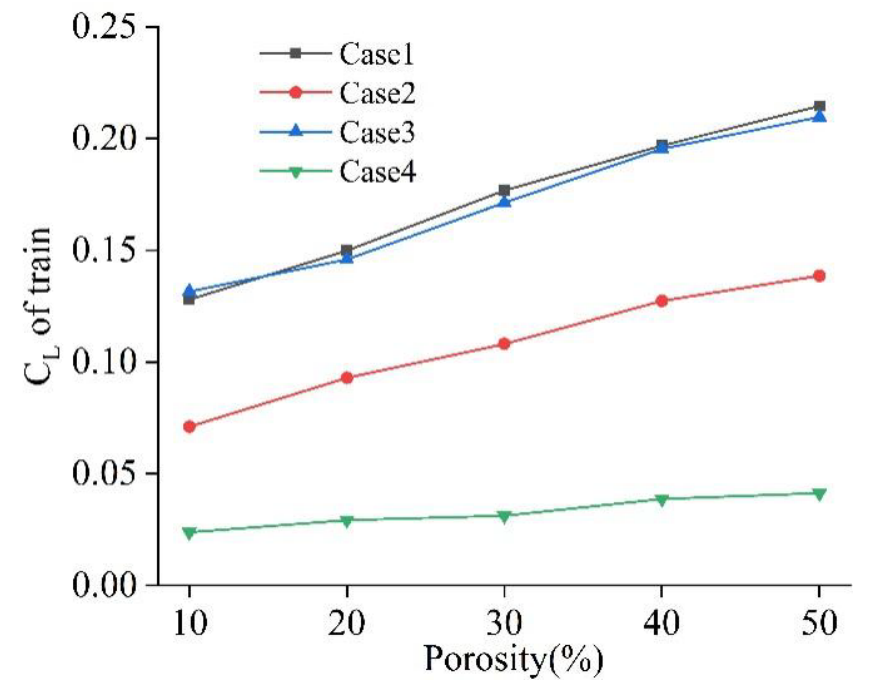

(b)

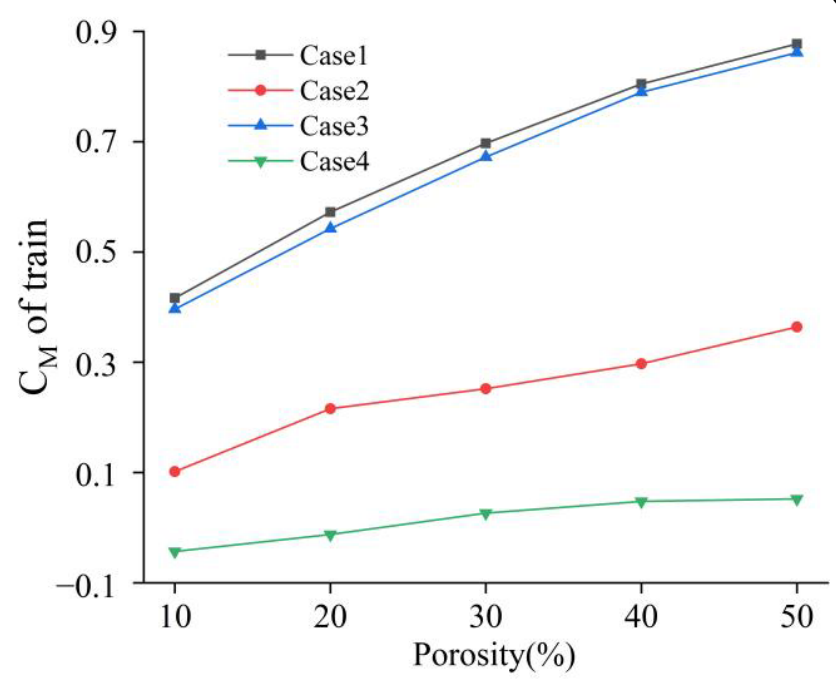

(c)

Figure 14. Influence of the porosity of the curved wind barrier on the aerodynamic force coefficients of the test train under different cases: (a) drag coefficient of the test train, (b) lift coefficient of the test train, (c) moment coefficient of the test train.

When there are trains (Case3, Case4) on both sides of the bridge, as shown in Figure 15c,d, the location of the test train has a significant impact on its wind pressure distributions. Whether there is a train on the leeward side of the bridge has little effect on the wind pressure coefficients of the test train arranged on the windward side of the bridge; there is almost no difference in wind pressure distribution between test trains of Case 1 and Case3. The test train of Case4 is completely immersed in the wake of the wind barrier and the train on the windward side of the bridge, which is less affected by the porosity of the wind barrier, and the wind pressure coefficients on each surface are at a relatively stable value. 


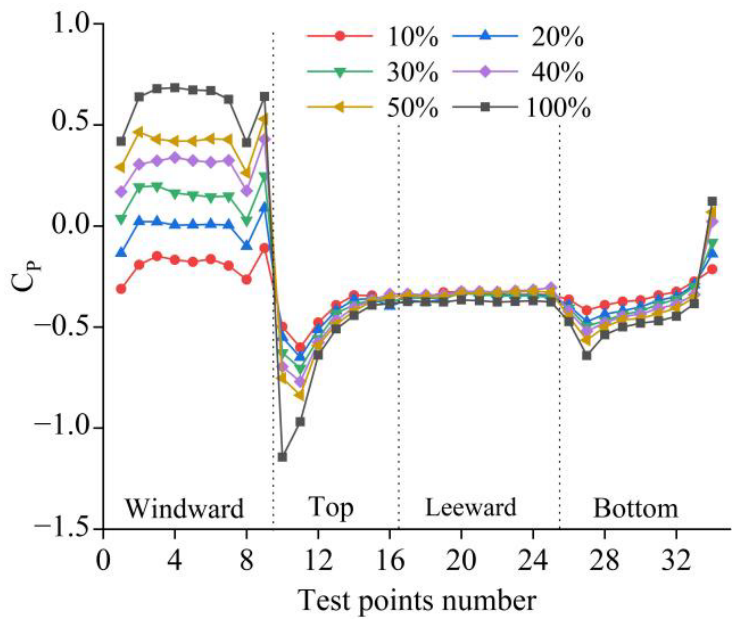

(a)

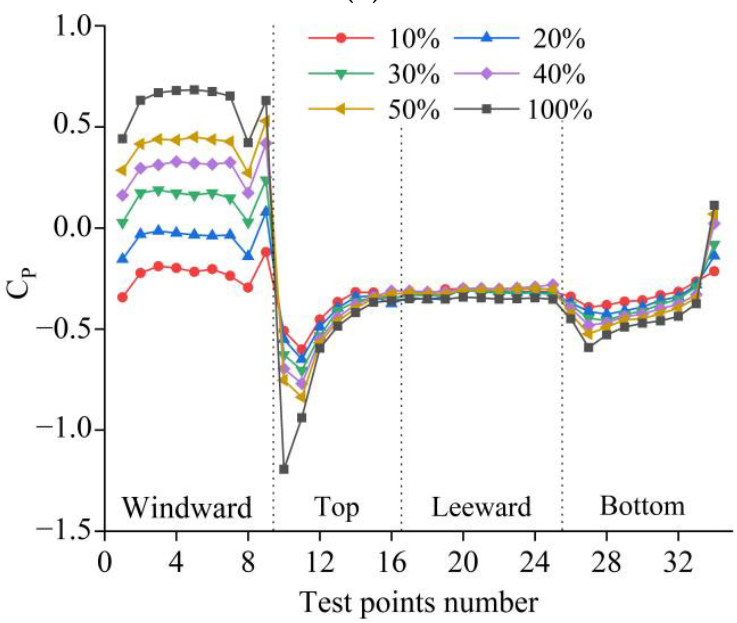

(c)

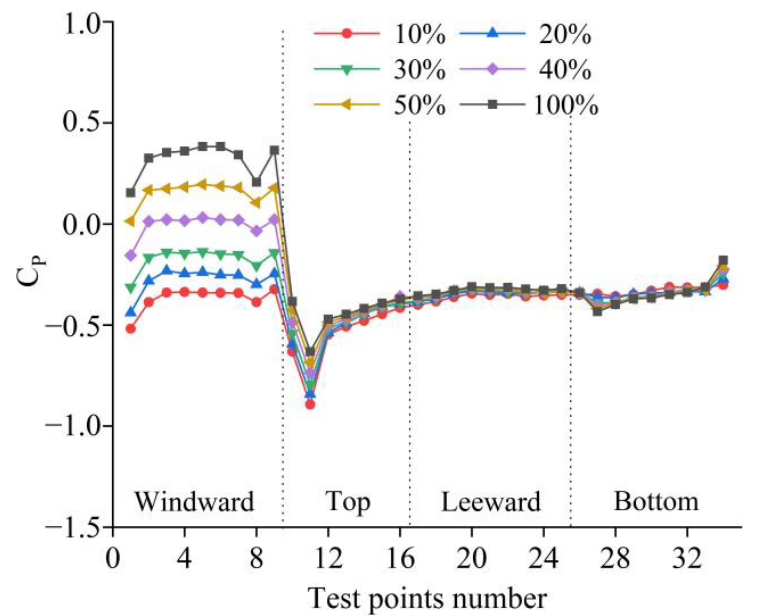

(b)

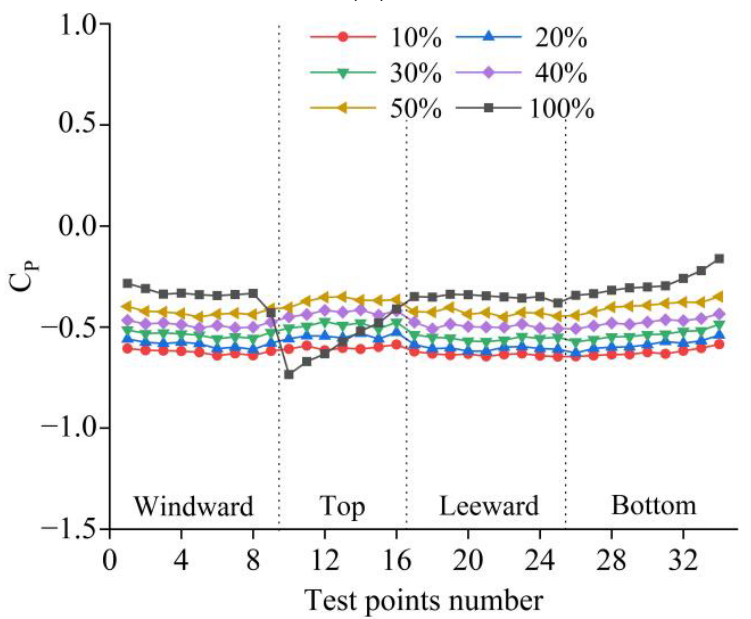

(d)

Figure 15. Influence of the porosity of curved wind barrier on the pressure coefficients of the train under different arrangements on the bridge: (a) $C_{P}$ of the test train in Case1, (b) $C_{P}$ of the test train in Case2, (c) $C_{P}$ of the test train in Case3, (d) $C_{P}$ of the test train in Case4.

\section{Conclusions}

A streamlined flat box girder and a Metro A-type train are taken as the background. The reliability numerical simulation is verified by wind tunnel tests, and the influence of curved wind barriers with four curvatures on crosswind aerodynamic characteristics of a train-bridge system are investigated by commercial CFD software ANYSY FLUENT 19.2. The main conclusions are drawn as follows.

(a) Curved wind barriers can effectively reduce the wind speed in the region below 1.5 times of the height of the wind barrier on the bridge deck. The $\mathrm{C} 4$ wind barrier with the largest curvature has the worst deceleration effect on the airflow and may cause strong interference to the flow field around the train. The $\mathrm{C} 1$ wind barrier with 0 curvature has the best effect on airflow deceleration, but after the $\mathrm{C} 1$ wind barrier is installed, the aerodynamic coefficients of the bridge increase significantly.

(b) The smaller the curvature of curved wind barrier, the stronger the protective effect on the train, but the greater the adversely impact on the wind resistance of the bridge. When the wind attack angle of airflow changes from negative to positive, the aerodynamic coefficients of train increase, while the aerodynamic coefficients of bridge decrease. The $\mathrm{C} 3$ wind barrier with a curvature of 0.35 can effectively reduce the aerodynamic coefficients and surface wind pressure of the train, and at the same 
time, has little impact on the wind resistance of the bridge; thus, it is more suitable for the safety protection of the train-bridge system in this study.

(c) The aerodynamic performance of the test train is greatly affected by the combinations of the train and bridge. When only a single test train is arranged on the bridge, whether on the windward side or leeward side of the bridge, the aerodynamic coefficient and surface wind pressure coefficient of the test train increase with the increase of the porosity of the wind barrier. The aerodynamic and wind pressure coefficients of the test train on the windward side of the bridge are larger than those of the test train on the leeward side of the bridge under the same conditions. When there are trains on both sides of the bridge, the aerodynamic performance of the test train on the windward side of the bridge is slightly affected by the train on the leeward side. However, the test train on the leeward side of the bridge is completely in the wake of the bridge, wind barrier, and train on the windward side. The aerodynamic and wind pressure coefficients are small and insensitive to the porosity of the curved wind barrier.

Author Contributions: Conceptualization, P.L.; methodology, W.T., C.C. and Y.A.; software, P.L., X.H. and Y.Z.; validation, W.T. and C.C.; formal analysis, P.L. and X.H.; investigation, Y.Z. and Y.A.; resources, Y.Z. and Y.A.; data curation, P.L., W.T. and C.C.; writing-original draft preparation, P.L., W.T. and C.C.; writing-review and editing, Y.Z. and Y.A.; visualization, X.H.; supervision, P.L. All authors have read and agreed to the published version of the manuscript.

Funding: The work described in this paper was supported by grants from the National Natural Science Foundation of China (Project nos. 52078501 and 51908554).

Institutional Review Board Statement: Not applicable.

Informed Consent Statement: Not applicable.

Data Availability Statement: Not applicable.

Conflicts of Interest: The authors declare no conflict of interest.

\section{References}

1. Baker, C. The flow around high speed trains. J. Wind Eng. Ind. Aerodyn. 2010, 98, 277-298. [CrossRef]

2. Suzuki, M.; Tanemoto, K.; Maeda, T. Aerodynamic characteristics of train/vehicles under cross winds. J. Wind Eng. Ind. Aerodyn. 2003, 91, 209-218. [CrossRef]

3. Baker, C.; Cheli, F.; Orellano, A.; Paradot, N.; Proppe, C.; Rocchi, D. Cross-wind effects on road and rail vehicles. Veh. Syst. Dyn. 2009, 47, 983-1022. [CrossRef]

4. Dorigatti, F.; Sterling, M.; Baker, C.J.; Quinn, A.D. Crosswind effects on the stability of a model passenger train-A comparison of static and moving experiments. J. Wind Eng. Ind. Aerodyn. 2015, 138, 36-51. [CrossRef]

5. Avila-Sanchez, S.; Lopez-Garcia, O.; Cuerva, A.; Meseguer, J. Characterisation of cross-flow above a railway bridge equipped with solid windbreaks. Eng. Struct. 2016, 126, 133-146. [CrossRef]

6. Zou, Y.F.; Fu, Z.Y.; He, X.H.; Cai, C.Z.; Zhou, J.; Zhou, S. Wind load characteristics of wind barriers induced by high-speed trains based on field measurements. Appl. Sci. 2019, 9, 4865. [CrossRef]

7. Xiang, H.Y.; Li, Y.L.; Chen, B.; Liao, H.L. Protection Effects of Railway Wind Barrier on Running Safety of Train Under Cross Winds. Adv. Struct. Eng. 2014, 17, 1177-1187. [CrossRef]

8. Hashmi, S.A.; Hemida, H.; Soper, D. Wind tunnel testing on a train model subjected to crosswinds with different windbreak walls. J. Wind Eng. Ind. Aerodyn. 2019, 195, 104013. [CrossRef]

9. Gu, H.Y.; Liu, T.H.; Jiang, Z.W.; Guo, Z.J. Reserach on the wind-sheltering performance of different forms of corrugated wind barriers on railway bridges. J. Wind Eng. Ind. Aerodyn. 2021, 217, 104735.

10. Kozmar, H.; Procino, L.; Borsani, A.; Bartoli, G. Sheltering efficiency of wind barriers on bridges. J. Wind Eng. Ind. Aerodyn. 2012, 107, 274-284. [CrossRef]

11. Kozmar, H.; Procino, L.; Borsani, A.; Bartoli, G. Optimizing height and porosity of roadway wind barriers for viaducts and bridges. Eng. Struct. 2014, 81, 49-61. [CrossRef]

12. He, X.H.; Wu, T.; Zou, Y.F.; Han, Y.; Shi, K. Aerodynamic characteristics of a trailing rail vehicles on viaduct based on still wind tunnel experiments. J. Wind Eng. Ind. Aerodyn. 2014, 135, 22-33. [CrossRef]

13. Zhang, T.; Xia, H.; Guo, W.W. Analysis on running safety of train on bridge with barriers subjected to cross wind. Wind Struct. 2013, 17, 203-225. [CrossRef] 
14. Deng, E.; Yang, W.C.; He, X.H.; Zhu, Z.H.; Wang, H.F.; Wang, Y.W.; Wang, A.; Zhou, L. Aerodynamic response of high-speed trains under crosswind in a bridge-tunnel section with or without a wind barrier. J. Wind Eng. Ind. Aerodyn. 2021, $210,104502$. [CrossRef]

15. Mohebbi, M.; Rezvani, M.A. Analysis of the effects of lateral wind on a high speed train on a double routed railway track with porous shelters. J. Wind Eng. Ind. Aerodyn. 2019, 184, 116-127. [CrossRef]

16. Guo, W.W.; Xia, H.; Karoumi, R.; Zhang, T.; Li, X.Z. Aerodynamic effect of wind barriers and running safety of trains on high-speed railway bridges under cross winds. Wind Struct. 2015, 20, 213-236. [CrossRef]

17. Buljac, A.; Kozmar, H.; Pospisil, S.; Machacek, M. Aerodynamic and aeroelastic characteristics of typical bridge decks equipped with wind barriers at the windward bridge-deck edge. Eng. Struct. 2017, 137, 310-322. [CrossRef]

18. Zhou, Q.; Zhu, L.D.; Guo, Z.S. Numerical simulation for curve windshield barrier effects on wind environment around bridge deck. J. Wuhan Univ. Technol. 2010, 32, 38-44 (In Chinese). (In Chinese)

19. Ogueta-Gutiérrez, M.; Franchini, S.; Alonso, G. Effects of bird protection barriers on the aerodynamic and aeroelastic behaviour of high speed train bridges. Eng. Struct. 2014, 81, 22-34. [CrossRef]

20. Spalart, P.R.; Deck, S.; Shur, M.L.; Squires, K.D. A new version of detached-eddy simulation, resistant to ambiguous grid densities. Theor Comp Fulid Dyn. 2006, 20, 181-195. [CrossRef]

21. Menter, F.R. Two-equation eddy-viscosity turbulence models for engineering applications. AIAA J. 1994, 32, 1598-1605. [CrossRef]

22. Zhao, D.X.; He, B.J. Effects of architectural shapes on surface wind pressure distribution: Case studies of oval-shaped tall buildings. J. Build. Eng. 2017, 12, 219-228. [CrossRef]

23. Telenta, M.; Duhovnik, J.; Kosel, F.; Sajn, V. Numerical and experimental study of the flow through a geometrically accurate porous wind barrier model. J. Wind Eng. Ind. Aerodyn. 2014, 124, 99-108. [CrossRef] 